VIOLETA RÉGNIER GALVÃO

\title{
Biomarcadores na anafilaxia a platinas
}

\author{
Tese apresentada à Faculdade de Medicina da \\ Universidade de São Paulo para obtenção do título \\ de Doutora em Ciências \\ Programa de Alergia e Imunopatologia \\ Orientador: Prof. Dr. Pedro Francisco Giavina- \\ Bianchi Junior
}

(Versão corrigida. Resolução CoPGr 6018/11, de 1 de novembro de 2011. A versão original está disponível na Biblioteca da FMUSP)

São Paulo 


\section{Dados Internacionais de Catalogação na Publicação (CIP)}

Preparada pela Biblioteca da

Faculdade de Medicina da Universidade de São Paulo

Creprodução autorizada pelo autor

Galvão, Violeta Régnier

Biomarcadores na anafilaxia a platinas / Violeta Régnier Galvão. -- São Paulo, 2017.

Tese (doutorado)--Faculdade de Medicina da

Universidade de São Paulo.

Programa de Alergia e Imunopatologia.

Orientador: Pedro Francisco Giavina-Bianchi Junior.

Descritores: 1.Neoplasias ginecológicas 2. Compostos de platina 3.Hipersensibilidade a drogas 4.Anafilaxia 5.Dessensibilização imunológica 6.Biomarcadores 7.Teste de ativação de basófilos 8. Genes BRCA1 9.Genes BRCA2 10.Triptases 


\section{Dedicatória}

À minha amada filha Angélica, fonte inesgotável de inspiração e de força: que este trabalho possa inspirá-la a sempre estudar e ser curiosa.

Ao meu amado esposo Rudolf, parceiro de vida na realização dos melhores sonhos e grande companheiro de vida acadêmica. 


\section{Agradecimentos}

À minha família, em especial aos meus pais, Claire e Galvão, por sempre me incentivarem a estudar e por me proporcionarem estímulos constantes de educação.

À minha filha Angélica, por ser minha incentivadora, até mesmo dentro da barriga.

Ao meu esposo Rudolf, por ser meu maior companheiro nesta jornada e, acima de tudo, um grande exemplo acadêmico.

Ao meu orientador, Professor Doutor Pedro Giavina-Bianchi, por sua visão inovadora e espírito científico. Agradeço a orientação, os ensinamentos, a paciência e a confiança.

À Professora Doutora Mariana Castells, pela orientação e pelo exemplo de cientista e médica. Agradeço pelo privilégio de ter desenvolvido a pesquisa em seu laboratório.

A todos os pacientes que passaram pela minha trajetória profissional, e em especial aos pacientes participantes da tese: esses, em momento de fragilidade pessoal e de forma altruísta, aceitaram participar do trabalho com a esperança de que ele possa auxiliar pacientes no futuro. 
A todos os assistentes e às preceptoras da Disciplina de Imunologia Clínica e Alergia da Faculdade de Medicina da Universidade de São Paulo pelos ensinamentos ao longo da residência e do doutorado.

A todos os professores que passaram pela minha trajetória escolar e acadêmica.

Aos meus gatos Paçoca, Peteca e Félix, companheiros fieis nos momentos de escrita. 


\section{Normalização adotada}

Esta tese está de acordo com as seguintes normas, em vigor no momento desta publicação:

Referências: adaptado de International Committee of Medical Journals Editors (Vancouver).

Universidade de São Paulo. Faculdade de Medicina. Divisão de Biblioteca e Documentação. Guia de apresentação de dissertações, teses e monografias. Elaborado por Anneliese Carneiro da Cunha, Maria Julia de A. L. Freddi, Maria

F. Crestana, Marinalva de Souza Aragão, Suely Campos Cardoso, Valéria Vilhena. 3a ed. São Paulo: Divisão de Biblioteca e Documentação; 2011.

Abreviaturas dos títulos dos periódicos de acordo com List of Journals Indexed in Index Medicus 


\section{Sumário}

Lista de figuras

Lista de tabelas

Lista de abreviaturas e siglas

Resumo

Abstract

1. INTRODUÇÃO

1.1 Câncer e reações adversas a quimioterápicos .................................... 2

1.2 Reações adversas a medicamentos e anafilaxia ................................. 4

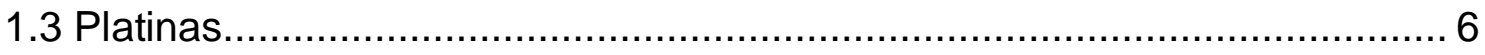

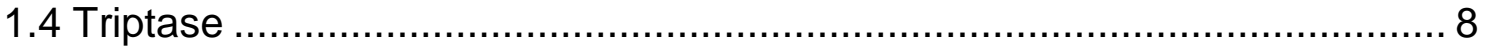

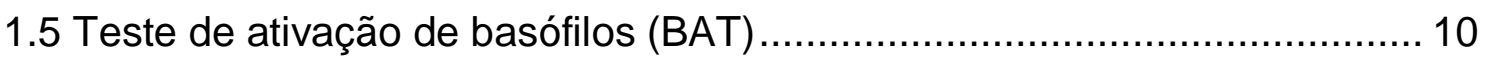

1.6 Dessensibilização a medicamentos: definição e mecanismos ................... 14

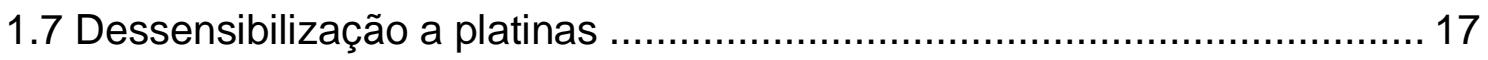

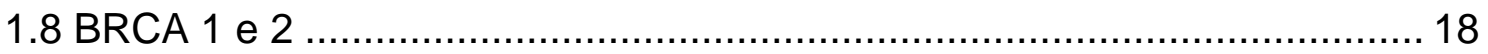

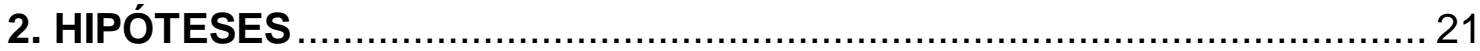

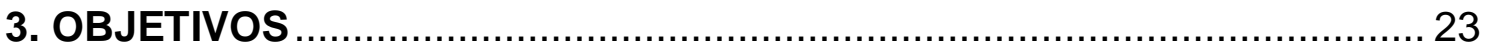

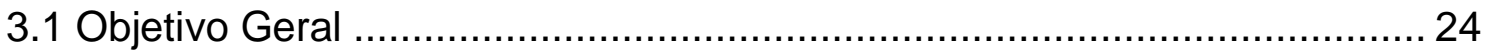

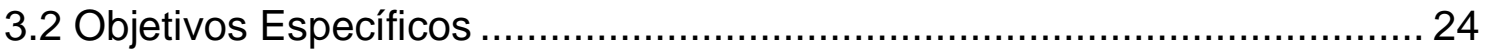

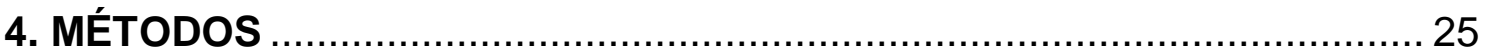

4.1 Estudo BAT - realização de BAT e pesquisa de triptase sérica: ................ 26

4.1.1 Casuística e delineamento ...................................................... 26

4.1.2 Classificação das reações de hipersensibilidade ........................... 29 
4.1.3 Protocolo de dessensibilização

4.1.4 Teste de ativação de basófilos (BAT) 32

4.1.5 Dosagem sérica de triptase 35

4.2 Estudo BRCA - análise de prevalência da mutação dos genes BRCA 1/2. 35

4.2.1 Pesquisa da mutação dos genes BRCA 1 e 2 36

4.3 Análise Estatística 36

5. RESULTADOS 36

5.1. Estudo BAT - realização de BAT e pesquisa de triptase sérica: 37

5.1.1 Caracterização das amostras 37

5.1.2 Dessensibilizações e triptase. 42

5.1.3 Teste de Ativação de Basófilos (BAT) 45

5.2. Estudo BRCA 55

6. DISCUSSÃO 59

7. CONCLUSÕES 73

8. ANEXO 76

9. REFERÊNCIAS 78 


\section{Lista de figuras}

Figura 1. Esquema simplificado ilustrando ativação e dessensibilização ........ 16

Figura 2. Análise Kaplan-Meier do risco de desenvolvimento de reações de hipersensibilidade à carboplatina em relação aos ciclos cumulativos de carboplatina. Os pacientes estão estratificados de acordo com a presença ou ausência da mutação BRCA 1/2 (adaptado de (106)) 20

Figura 3. Delineamento geral do estudo BAT

Figura 4. Exemplo de resultado positivo do BAT expresso por gMFI (média geométrica de intensidade de fluorescência): avaliação das expressões de CD63 e CD203c após incubação com solução salina (controle negativo) e carboplatina $500 \mu \mathrm{l} / \mathrm{ml}$ em paciente alérgica. 48

Figura 5. Exemplo de resultado positivo do BAT dado pelo percentual de células com expressão de CD63 e CD203c, após incubação com solução salina e carboplatina $500 \mu \mathrm{l} / \mathrm{ml}$ em paciente alérgica à carboplatina. 49

Figura 6. Expressão de CD203c nos grupos de pacientes alérgicas às platinas, grupo controle 1 (tolerantes à carboplatina) e grupo controle 2 (voluntários nunca expostos às platinas). 50 
Figura 7. Expressão de CD63 nos grupos de pacientes alérgicas às platinas, grupo controle 1 (tolerantes à carboplatina) e grupo controle 2 (voluntários nunca expostos às platinas) 51

Figura 8. Exemplo de resultado negativo do BAT expresso por gMFI (média geométrica de intensidade de fluorescência). 52

Figura 9. Exemplo de resultado negativo do BAT dado pelo percentual de células com expressão de CD63 e CD203c, após incubação com solução salina (controle negativo), carboplatina, e anti-lgE + carboplatina (controle positivo) em paciente tolerante à carboplatina 53

Figura 10. Evolução da expressão de CD203c e CD63 avaliada por meio do índice de estimulação em paciente alérgica à carboplatina submetida a múltiplas dessensibilizações 54

Figura 11. (a) Incidência de reações de hipersensibilidade imediata entre pacientes portadoras e não portadoras da mutação do BRCA 1/2. (b) Distribuição da gravidade das reações de hipersensibilidade iniciais à carboplatina entre portadoras e não portadoras da mutação do BRCA 1/2 .... 57

Figura 12. (a) Incidência de reações de hipersensibilidade imediata durante dessensibilização à carboplatina entre portadoras e não portadoras da mutação do BRCA 1/2. (b) Graus das reações ocorridas durante a dessensibilização entre portadoras e não portadoras da mutação do BRCA 1/2. (c) Média dos 
níveis de triptase durante reações de hipersensibilidade imediata ocorridas durante dessensibilização à carboplatina, em pacientes portadoras e não portadoras da mutação do BRCA $1 / 2$ (valor de referência $\leq 11,5 \mu \mathrm{g} / \mathrm{L}$ ) ............58 


\section{Lista de tabelas}

Tabela 1. Classificação das reações de hipersensibilidade imediata 29

Tabela 2. Exemplo de protocolo de dessensibilização a medicamentos - 3 soluções e 12 etapas.

Tabela 3. Concentrações seriadas de carboplatina e oxaliplatina utilizadas no teste de ativação de basófilos 34

Tabela 4. Estudo BAT: caracterização geral das pacientes alérgicas e das reações de hipersensibilidade imediata. 39

Tabela 5. Dados gerais dos três grupos do estudo BAT: pacientes alérgicas, controle 1 e controle 2 40

Tabela 6. Desfecho da dessensibilização e resultados do BAT. 44 


\section{Lista de abreviaturas e siglas}

ABNT: Associação Brasileira de Normas Técnicas

APC: Aloficocianina

BAT: Teste de Ativação de Basófilos

BSA: Albumina Bovina Sérica

BV: Brilliant Violet

BWH: Brigham and Women's Hospital

CD123: Receptor de Interleucina-3

CD203c: Ectoenzima Basofílica E-NPP3

CD41: Integrina alfa Ilb

CD63: Glicoproteína CD63

DFCl: Dana-Farber Cancer Institute

DP: desvio padrão

EUA: Estados Unidos da América

FACS: Fluorescence Activated Cell Sorting

FcERI: Receptor de Alta Afinidade para Imunoglobulina E FITC: Isotiocianato de Fluoresceína

gMFI: Média Geométrica de Intensidade de Fluorescência

HLA: Antígeno Leucocitário Humano

ID: Intradérmico

lgE: Imunoglobulina $\mathrm{E}$

IgG: Imunoglobulina G

MFI: Intensidade de Fluorescência Média

NET: Necrólise Epidérmica Tóxica

No.: Número

PAS: Pressão Arterial Sistólica

PBS: Tampão Fosfato-Salino

PE: Ficoeritrina

QT: Quimioterápico

RNA: Ácido Ribonucleico

SpO2: Saturação Periférica de Oxigênio

STAT-6: Transdutor de Sinal e Ativador de Transcrição-6

USP: Universidade de São Paulo 
Galvão VR. Biomarcadores na anafilaxia a platinas [tese]. São Paulo: Faculdade de Medicina, Universidade de São Paulo; 2017.

\section{Resumo}

INTRODUÇÃO: O câncer constitui-se na principal causa de mortalidade entre indivíduos de 45 a 84 anos, configurando-se em um dos principais problemas de saúde pública dos países em desenvolvimento. As reações de hipersensibilidade aos quimioterápicos têm aumentado, impedindo muitas vezes a utilização de terapias de primeira linha no tratamento de neoplasias primárias ou recidivantes. O procedimento de dessensibilização é uma abordagem alternativa, por meio do qual o paciente passa a tolerar a medicação que antes desencadeava reações potencialmente letais. Quimioterápicos do grupo das platinas são exemplos de drogas passíveis de readministração por meio do processo de dessensibilização, no entanto faltam biomarcadores preditivos de reações durante o procedimento. OBJETIVOS: O objetivo principal do estudo foi avaliar o papel do teste de ativação de basófilos (BAT) como biomarcador para reações de hipersensibilidade ocorridas durante a dessensibilização em pacientes alérgicas às platinas. Como objetivo secundário, avaliou-se a prevalência e o impacto da mutação dos genes BRCA 1 e 2 em pacientes com hipersensibilidade imediata à carboplatina submetidas à dessensibilização. MÉTODOS: Padronizou-se o BAT, com análise da expressão de CD63 e CD203c na superfície de basófilos de pacientes com hipersensibilidade imediata às platinas submetidas à dessensibilização. Foram realizados BATs em 15 pacientes portadoras de neoplasias malignas 
submetidas a 27 dessensibilizações devido à anafilaxia a quimioterápico do grupo das platinas e em 12 indivíduos de dois grupos controle (Grupo 1: seis pacientes tolerantes às platinas e Grupo 2: seis voluntários sadios que nunca foram expostos às platinas). Os resultados dos BATs foram comparados entre os três grupos. Correlacionou-se o BAT com a ocorrência ou não de reação durante a dessensibilização e com os níveis de triptase sérica. Para análise da prevalência e impacto da mutação dos genes BRCA 1 e 2 nas dessensibilizações, realizou-se análise retrospectiva de prontuários de 138 portadoras de neoplasias malignas ginecológicas submetidas à dessensibilização à carboplatina. RESULTADOS: O BAT foi positivo em 11 das 15 pacientes alérgicas $(n=11 ; 73,3 \%)$, com aumento de expressão de CD203c e CD63 em $11(73,3 \%)$ e 6 (40\%) pacientes, respectivamente. Todos os participantes dos grupos controles apresentaram testes negativos. Maior expressão de CD63 foi observada em pacientes com reações iniciais mais graves. O BAT foi positivo em $92,3 \%$ das reações ocorridas durante as dessensibilizações $(n=12 / 13)$, sendo positivo em todas as reações que apresentaram aumento concomitante de triptase sérica $(n=5)$. Com relação à mutação dos genes BRCA 1 e 2, sua prevalência foi de $34 \%$ nas pacientes com hipersensibilidade às platinas $(n=47 / 138)$, sendo que $51 \%$ das portadoras reagiram durante a dessensibilização. CONCLUSÕES: O BAT positivo, com aumento da expressão de CD63 e/ou CD203c na superfície do basófilo, identificou pacientes alérgicos às platinas com especificidade de 100\% e sensibilidade de 73,3\%. O BAT e a mutação dos genes BRCA 1 e 2 identificaram pacientes mais propensos a reagir durante o procedimento de dessensibilização. A utilização de biomarcadores preditores de reações durante 
a dessensibilização aos quimioterápicos do grupo das platinas pode aumentar a segurança do procedimento e auxiliar na manutenção do esquema quimioterápico de primeira linha do paciente.

Descritores: neoplasias ginecológicas; compostos de platina; hipersensibilidade a drogas; anafilaxia; dessensibilização imunológica; biomarcadores; teste de ativação de basófilos; genes BRCA1; genes BRCA2; triptases. 
Galvão VR. Biomarkers of anaphylaxis to platinum-based agents [thesis]. São Paulo: "Faculdade de Medicina, Universidade de São Paulo"; 2017.

\section{Abstract}

INTRODUCTION: Cancer is the leading cause of death in the age group of 45 to 84 years, and one of the main public health issues in developing nations. Hypersensitivity reactions to chemotherapeutic agents have been increasing, sometimes hindering the use of first-line therapies in the treatment of primary or relapsed tumors. Rapid drug desensitization (RDD) is an alternative approach, through which a patient becomes tolerant to the medication that once triggered a potentially lethal hypersensitivity reaction. Platinum-based compounds are examples of drugs that can be readministered through the desensitization procedure, but currently there are no known biomarkers that could help predict reactions during RDD. OBJECTIVES: The main goal of our study was to assess the basophil activation test (BAT) as a biomarker of breakthrough reactions occurred during RDD in patients allergic to platinum-based agents. As a secondary goal, we evaluated the prevalence and impact of the BRCA $1 / 2$ mutation in carboplatin-allergic patients undergoing RDD. METHODS: We standardized the BAT by evaluating CD63 and CD203c expressions on the basophils of patients with immediate hypersensitivity reactions to platinumbased agents undergoing RDD. We analyzed BATs of 15 patients with malignant neoplasms who had undergone 27 RDD procedures due to anaphylaxis to platinum-based agents, and of 12 control subjects (Group 1: six 
patients tolerant to platinum-based agents, and Group 2: six healthy volunteers who had never been exposed to platinum-based agents). BAT results were compared among the three groups. We correlated BAT results with the occurrence of breakthrough reactions during RDD and with serum tryptase levels. To conduct the analysis of the BRCA $1 / 2$ mutation prevalence and its impact on RDD, a retrospective review of 138 medical records of patients with gynecological malignancies who underwent RDD to carboplatin was performed. RESULTS: BAT was positive in 11/15 allergic patients (73.3\%), with increased expression of CD203c and CD63 in 11 (73.3\%) and 6 (40\%) patients, respectively. All control subjects presented negative BATs. A higher CD63 expression was observed in patients with severe initial reactions. BAT was positive in $92.3 \%$ of the breakthrough reactions occurred during RDD ( $n=12 / 13)$, and in all reactions with concomitant increased tryptase levels $(n=5)$. Regarding the BRCA1/2 mutation, its prevalence was $34 \%$ in patients allergic to platinumbased agents $(n=47 / 138)$, and $51 \%$ of the mutation carriers had breakthrough reactions during RDD. CONCLUSIONS: A positive BAT, with an increased expression of CD63 and/or CD203c, identified patients allergic to platinumbased agents with a specificity of $100 \%$ and a sensitivity of $73.3 \%$. The BAT and the BRCA $1 / 2$ mutation helped identify patients at risk of breakthrough reactions during RDD. The use of predictive biomarkers of breakthrough reactions during RDD to platinum-based agents might enhance RDD safety and help maintain a patient`s first-line treatment. 
Descriptors: gynecologic neoplasms; platinum compounds; drug hypersensitivity; anaphylaxis; desensitization, immunologic; biomarkers; basophil activation test; genes, BRCA1; genes, BRCA2; tryptases. 
1. INTRODUÇÃO 


\subsection{Câncer e reações adversas a quimioterápicos}

As neoplasias malignas constituem-se nas principais causas de mortalidade entre indivíduos de 45 a 84 anos [1-3]. Sua incidência e mortalidade estão aumentando nos países em desenvolvimento, acarretando impacto socioeconômico imensurável. Segundo estimativas mundiais da Agência Internacional para Pesquisa em Câncer, em 2012, houve 14,1 milhões de casos novos de câncer e um total de 8,2 milhões de mortes por câncer em todo o mundo [4]. Destes casos novos estimados, mais de $60 \%$ ocorreram em países em desenvolvimento, e, dentre os óbitos relatados, 70\% ocorreram nesses mesmos países. A estimativa de casos novos de neoplasias malignas no Brasil para o biênio 2016-2017 é de cerca de 600.000, reforçando a magnitude do problema do câncer no país [5].

Dividindo-se por subtipos, o câncer de pele do tipo não melanoma é o mais incidente na população brasileira (180 mil casos novos), seguido pelos tumores de próstata $(61 \mathrm{mil})$, mama feminina $(57 \mathrm{mil})$, cólon e reto (34 mil), pulmão (28 mil), estômago (20 mil) e colo do útero (16 mil) [5]. Dentre as neoplasias malignas ginecológicas, destaca-se o câncer de ovário devido à sua alta morbimortalidade. Em 2016, houve cerca de 6150 novos casos no país, correspondendo ao sétimo tipo mais incidente nas mulheres [5]. Nos EUA, esta neoplasia corresponde à principal causa de óbito entre cânceres ginecológicos e à quinta causa de óbitos secundários a câncer em mulheres [6].

As reações adversas aos quimioterápicos em pacientes com câncer também têm aumentado dramaticamente em todo o mundo, impedindo muitas 
vezes a utilização de terapias de primeira linha no tratamento da neoplasia primária ou recidivante [7-10]. Embora diversos fatores possam estar associados a este aumento, como a maior sobrevida dos pacientes e a exposição contínua a medicamentos sensibilizantes, ainda há muito a ser elucidado [11]. O uso de medicações profiláticas antes da quimioterapia, como corticosteroides e anti-histamínicos ou a redução na velocidade de infusão do quimioterápico muitas vezes não previne o desencadeamento de reações alérgicas, o que ocasiona a suspensão definitiva do esquema de tratamento [8, 12].

Diferentes tipos de quimioterápicos desencadeiam reações de hipersensibilidade distintas. O grupo dos taxanos, cujos principais agentes são o paclitaxel e o docetaxel, são utilizados para tratamento de neoplasias malignas de ovário, endométrio, mama, pulmão, cabeça e pescoço, pâncreas, estômago e próstata. Acredita-se que haja mais de um mecanismo imunológico nas reações de hipersensibilidade imediatas aos taxanos [13]. As reações tendem a ocorrer na primeira ou segunda infusão, e envolvem desde sintomas e sinais típicos de reações imediatas IgE-mediadas até sintomas atípicos como dor precordial, dorsalgia e dor pélvica. São descritas reações IgE-mediadas e ativação mastocitária/basofílica direta (anafilaxia não alérgica). Os solventes das moléculas dos taxanos (cremophor no paclitaxel e polissorbato 80 no docetaxel) podem levar à ativação do sistema complemento, levando à produção de anafilatoxinas e ativação mastocitária [13]. 
O grupo das platinas, com seus principais representantes carboplatina e oxaliplatina, desencadeiam majoritariamente reações lgE-mediadas após quatro a oito ciclos e serão discutidas em detalhe adiante [13, 14].

\subsection{Reações adversas a medicamentos e anafilaxia}

Reações adversas a medicamentos (RAMs) são reações indesejáveis e não intencionadas que ocorrem devido ao uso de uma determinada medicação, em doses farmacológicas, para fins terapêuticos, profiláticos ou diagnósticos [15]. Dentre as RAMs, destaca-se a reação de hipersensibilidade, um subtipo de RAM com sintomas objetivos que podem ser reproduzidos em contatos subsequentes com o medicamento envolvido [15]. As reações de hipersensibilidade ocorrem de forma imprevisível, deixam sequelas psíquicas e físicas nos pacientes e podem ser fatais. São divididas em reações imediatas e não imediatas, dependendo do tempo transcorrido entre a exposição do medicamento e o início da reação; tradicionalmente considera-se o período de até uma hora para reações imediatas, mas, nos últimos anos, alguns especialistas advogam que esse tempo deva ser de seis horas [16, 17]. As reações de hipersensibilidade apresentam diferentes fisiopatologias e podem ser alérgicas, quando há resposta imune específica contra o medicamento, ou não alérgicas [15].

Em meio às reações de hipersensibilidade imediata, a anafilaxia se destaca como reação grave, de início rápido e potencialmente letal $[15,18]$. É caracterizada como uma reação sistêmica que acomete vários órgãos e 
sistemas simultaneamente e é determinada pela atividade de mediadores farmacológicos liberados por mastócitos e basófilos ativados [19]. Seu diagnóstico é baseado na história clínica do paciente associada ao reconhecimento de padrões de apresentação clínica já estabelecidos [20]. A anafilaxia pode ocorrer tanto por mecanismos imunológicos (alérgicos), como também por mecanismos não imunológicos (não alérgicos) [15, 18]. A anafilaxia de origem alérgica é aquela que envolve mecanismos imunológicos específicos, podendo ser lgE ou não IgE-mediada (com envolvimento de IgG ou de imunocomplexos, demonstrados apenas em camundongos) [15, 18, 20 22]. A anafilaxia de etiologia não alérgica ocorre sem resposta imune específica e entre seus mecanismos conhecidos podem-se incluir a ativação do sistema complemento com consequente produção de anafilatoxinas, a disfunção do metabolismo do ácido araquidônico e a ativação direta de mastócitos [23].

Estudos demonstram o papel das medicações como principais causas de reações anafiláticas e de anafilaxias letais [10, 24-27]. Análise de 634 pacientes latino-americanos que apresentaram quadro de anafilaxia entre 2008 e 2010 evidenciou como principais desencadeantes os medicamentos, reportados em $31,2 \%$ dos casos. Antibióticos, anti-inflamatórios não esteroidais, relaxantes neuromusculares e contrastes iodados encontram-se entre os principais causadores de anafilaxias induzidas por drogas, com variações na ordem de prevalência de acordo com o país estudado [25, 26, 28, 29].

Em estudo de 2009, foi evidenciado aumento significativo das anafilaxias letais por medicamentos na Austrália [24]. Nos EUA, em 2014, foi publicada 
análise das principais causas de mortes por anafilaxia no período de 1999 a 2010 [10]. Os medicamentos foram os principais causadores dessas anafilaxias letais, sendo os quimioterápicos o terceiro grupo mais implicado [10]. Fatores de risco conhecidos para anafilaxias letais induzidas por medicamentos incluem idade superior a 50 anos e a presença de comorbidades cardiovasculares [30, 31].

\subsection{Platinas}

Os quimioterápicos do grupo das platinas são considerados medicamentos de primeira linha para o tratamento de neoplasias malignas ovarianas e de outras neoplasias sólidas [11,32, 33]. A cisplatina foi o primeiro do grupo a ser largamente utilizado, mas devido à maior toxicidade (neurotoxicidade e nefrotoxicidade) associada ao fármaco, seu uso foi reduzido na última década, dando lugar ao composto de segunda geração carboplatina [34]. Dada sua grande eficácia em tratamentos de primeira e segunda linhas e de resgate para o câncer de ovário, a carboplatina vem sendo amplamente utilizada, o que contribuiu para o aumento na incidência de reações de hipersensibilidade ao medicamento [35]. A oxaliplatina é um composto de terceira geração e considerado terapia de primeira linha para o câncer colorretal [36] e pancreático [37, 38], com sua indicação sendo ampliada para neoplasias malignas ginecológicas resistentes aos compostos de primeira e segunda linha [39]. 
Devido ao uso difundido destes fármacos e grande exposição aos mesmos, a incidência geral de reações de hipersensibilidade a platinas tem sofrido aumento significativo [34, 40]. Estima-se atualmente que reações de hipersensibilidade à cisplatina ocorram em 5 a $20 \%$ dos pacientes, à carboplatina em 9 a $47 \%$ e à oxaliplatina em 10 a 19\% dos doentes [11, 34, 41].

Reações alérgicas à carboplatina tendem a ocorrer a partir do oitavo ciclo de administração da droga [11, 34, 35], enquanto que reações alérgicas à cisplatina e à oxaliplatina ocorrem principalmente entre o quarto e oitavo ciclo e após o sexto ciclo, respectivamente [11, 14, 34]. A incidência de reações à carboplatina aumenta com o número de ciclos de infusão dos pacientes: menos de $1 \%$ naqueles que receberam seis ciclos ou menos e $47 \%$ nos que receberam sete ou mais ciclos [41]. O intervalo sem medicação também é fator de risco para o desenvolvimento de reações de hipersensibilidade à carboplatina [41]. Período de 12 a 24 meses entre duas administrações de carboplatina relacionou-se a risco de reação de hipersensibilidade à droga de $56,5 \%$, mais que o dobro do observado quando o intervalo era menor que 12 meses $(25,8 \%)$. Considerando-se apenas reações graves, este risco chega a valores quase quatro vezes maiores, passando de $6,5 \%$ para $23,9 \%$ [41].

Apesar do avanço no conhecimento dos mecanismos fisiopatológicos envolvidos nas reações alérgicas a platinas, ainda há aspectos a serem elucidados. A observação de testes cutâneos de leitura imediata positivos e a presença de lgE sérica específica em pacientes que apresentam reações demonstram a participação de mecanismo IgE mediado [11, 42], assim como a 
necessidade de múltiplas exposições e a manifestação clínica imediata após a administração do medicamento. Em alguns casos com apresentação clínica tardia, sugere-se a participação de mecanismo de hipersensibilidade tipo IV [14]. Trombocitopenia mediada por reação de hipersensibilidade do tipo II e urticária mediada por hipersensibilidade tipo III foram reportadas associadas ao uso de oxaliplatina [43].

A apresentação clínica de reações de hipersensibilidade imediata às platinas é variada, e envolve desde sinais e sintomas cutâneos como eritema, rubor, urticária, angioedema e prurido, até sinais e sintomas respiratórios, cardiovasculares e relacionados ao trato digestório [8, 14]. Em avaliação de sessenta pacientes com reações secundárias à carboplatina, Castells et al relataram manifestações cutâneas em 100\% destes pacientes, cardiovasculares em 57\%, respiratórias em $40 \%$ e gastrointestinais em $42 \%$ [8]. A oxaliplatina tende a ocasionar reações de menor gravidade, com predomínio cutâneo e respiratório conforme avaliação de 39 casos de reações alérgicas imediatas à medicação [43].

\subsection{Triptase}

Pacientes alérgicos a quimioterápicos podem apresentar anafilaxias graves, com aumento de triptase sérica, que representa um marcador de ativação e desgranulação de mastócitos e basófilos [11, 44, 45]. Embora 0 diagnóstico de anafilaxia seja baseado na história e quadro clínico, a 
mensuração da triptase sérica fornece informações adicionais e corrobora o diagnóstico.

A triptase é uma protease de mastócitos e basófilos liberada em reações de hipersensibilidade imediata e níveis superiores a $25 \mu \mathrm{g} / \mathrm{L}$ sugerem fortemente mecanismo IgE-mediado (valor de referência $\leq 11,5 \mu \mathrm{g} / \mathrm{L}$ ) [46]. Ela também se eleva em casos de ativação mastocitária não imunológica, mas seu aumento tende a ser menos frequente e menos pronunciado $[47,48]$. Por outro lado, reações imediatas podem se apresentar com níveis de triptase normais, o que pode ser devido a anafilaxias secundárias à liberação de mediadores de basófilos [49-51]. É pertinente relatar ainda que os níveis de triptase são menores em mastócitos de mucosas do que em mastócitos cutâneos e perivasculares, portanto espera-se que reações anafiláticas secundárias a drogas de administração intravenosa levem a aumentos mais significativos e persistentes de triptase sérica do que aquelas ocasionadas por alérgenos alimentares, por exemplo [22].

A meia-vida da triptase é de aproximadamente duas horas, retornando aos valores basais dentro de 12 a 14 horas [52]. O melhor momento para obtenção de amostra de sangue do paciente é de 30 a 120 minutos após o início da reação [50, 52-54], sendo que alguns autores aumentam este intervalo de tempo para até seis horas [55]. Caso os níveis iniciais estejam elevados, o diagnóstico de anafilaxia é provável, mas outra amostra de sangue deverá ser coletada para comparação pelo menos dois dias após a resolução do quadro [49]. Isto se deve ao fato de que os valores normais basais podem apresentar variações entre os pacientes e à existência de condições que 
aumentam os níveis basais, como a mastocitose sistêmica (em que um dos critérios diagnósticos são níveis basais de triptase $\geq 20 \mu \mathrm{g} / \mathrm{L}$ ) e a síndrome de ativação mastocitária [46, 49, 55-57]. Pacientes que apresentam níveis basais considerados normais de triptase $(\leq 11,5 \mu \mathrm{g} / \mathrm{L})$ podem apresentar aumento destes níveis durante anafilaxias sem atingir o valor de corte, por isso também são considerados alterados valores superiores a $1,2 x$ do basal $+2 \mu \mathrm{g} / \mathrm{L}[58]$.

\subsection{Teste de ativação de basófilos (BAT)}

Os basófilos são um dos tipos celulares menos abundantes no sangue, correspondendo a menos de $1 \%$ dos leucócitos circulantes, e estão envolvidos nos mecanismos imunológicos de processos alérgicos e infecções helmínticas. O basófilo, assim como o mastócito, possui receptores de alta afinidade para os anticorpos lgE circulantes (FcERI) em sua membrana celular e seu papel nas anafilaxias tem sido cada vez mais estudado [59].

Quando um determinado alérgeno promove ligação cruzada entre duas IgEs que estão unidas aos basófilos, é desencadeada uma cascata de reações que culmina na liberação de mediadores inflamatórios pré-formados, existentes nos grânulos citoplasmáticos, e neoformados. Esta desgranulação não ocorre somente em reações mediadas por IgE, podendo também ser desencadeada por outros estímulos para os quais o basófilo possua receptores [60]. Foram demonstradas redução do número de basófilos circulantes e migração tecidual, evidenciadas pela redução dos níveis séricos de basófilos e aumento de CCL2 (fator quimiotático de basófilos), em pacientes que se apresentaram ao pronto 
socorro com quadro de anafilaxia secundária à ferroada por himenópteros e em pacientes alérgicos a amendoim que reagiram clinicamente durante provocação oral [59].

A ativação dos basófilos pode ser detectada por meio do marcador CD63, uma glicoproteína pouco abundante na membrana celular de basófilos em repouso, mas presente em grande quantidade nas membranas de seus grânulos citoplasmáticos armazenadores de mediadores pró-inflamatórios [61]. Quando ocorre a ativação dos basófilos, há fusão das membranas dos grânulos com a membrana celular, liberação dos mediadores pré-formados e aumento do número de moléculas CD63 na superfície celular [61, 62]. A molécula CD63 não é específica de basófilos, sendo também encontrada em plaquetas, eosinófilos e monócitos [60]. Outra molécula usada mais recentemente para caracterizar a ativação basofílica é o CD203c [63], que é expressa exclusivamente na membrana de basófilos e mastócitos [64]. Ao contrário do CD63, o CD203c apresenta uma expressão basal em basófilos em repouso, que aumenta significativamente durante a ativação [65]. O teste de ativação de basófilos (BAT) baseado em citometria de fluxo é utilizado neste contexto, pois por meio dele é possível aferir a expressão tanto de CD63 quanto de CD203c na população de basófilos avaliada. Alguns autores referem sensibilidade aumentada do BAT com o uso de marcação específica para o CD203c [66, 67], enquanto outros relatam o oposto [68-70].

Tendo em vista o papel dos basófilos nas reações de hipersensibilidade, diversas pesquisas têm estudado e utilizado o BAT como ferramenta diagnóstica em diferentes reações de hipersensibilidade [59, 71-74]. Exemplos 
incluem alergia à proteína do leite de vaca [71, 72], hipersensibilidade ao veneno de himenópteros [75], hipersensibilidade aos alérgenos do gato [76] e hipersensibilidade a medicamentos.

Algumas das possíveis indicações do BAT na prática clínica incluem: história clínica sugestiva de reação IgE-mediada com teste cutâneo de leitura imediata negativo e lgE sérica específica indetectável; história sugestiva de reação IgE-mediada com teste cutâneo e IgE sérica discordantes; história sugestiva de reação IgE-mediada sem disponibilidade de investigação por meio de $\lg$ E sérica específica e extrato para teste cutâneo não padronizado, ou suspeito de desencadear reação cutânea irritativa [60].

Em 2014 foi demonstrado que alérgenos recombinantes do veneno de vespa aplicados ao BAT aumentaram a especificidade do diagnóstico in vitro de hipersensibilidade ao veneno [75]. O BAT também foi útil em identificar o veneno ao qual determinado paciente era alérgico, quando os testes cutâneos e IgE sérica específica eram inconclusivos [77]. Em pacientes portadores de mastocitose e suspeita de alergia ao veneno de vespa, o papel do BAT em identificar os pacientes alérgicos foi demonstrado, apresentando $100 \%$ de especificidade [78].

Ao avaliar a gravidade de um processo alérgico, a reatividade basofílica verificada por meio do BAT correlacionou-se com a gravidade clínica da alergia à proteína do leite de vaca, encontrando-se aumentada em pacientes com quadros mais graves, ou seja, naqueles que não toleravam produtos à base de leite cozido ("baked-milk products") [71]. O uso do BAT na avaliação do desenvolvimento de tolerância ao leite de vaca foi demonstrado em estudo que 
avaliou 112 crianças alérgicas submetidas à provocação oral. Pacientes com testes de provocação positivos apresentaram expressão de CD63 significativamente superior quando comparados com aqueles com testes negativos, sugerindo o potencial do BAT como uma ferramenta adicional para verificação de tolerância e para tornar procedimentos de provocação mais seguros [79].

Ácido acetilsalicílico, beta-lactâmicos, quinolonas, bloqueadores neuromusculares, agentes biológicos e quimioterápicos antineoplásicos são exemplos de medicamentos em que estudos foram publicados utilizando o BAT como ferramenta adicional de investigação [53, 80-86]. Em relação aos betalactâmicos, estudos demonstraram a sensibilidade do BAT variando de $28,6 \%$ a $55 \%$, com especificidade de $93,3 \%$ [80, 87]. Quando usado em conjunto com a IgE sérica específica, o método permitiu a identificação de $65,5 \%$ dos pacientes alérgicos a beta-lactâmicos que apresentavam testes cutâneos positivos com pelo menos um alérgeno de beta-lactâmico [87]. Em relação aos bloqueadores neuromusculares (rocurônio), o uso do BAT como ferramenta auxiliar para fornecimento de alternativas seguras e exclusão de reatividade cruzada foi estudado com sucesso [85].

Há poucas publicações a respeito da aplicação do BAT em casos de alergia a quimioterápicos do grupo das platinas. Um relato de caso foi publicado abordando o uso do BAT em um caso suspeito de alergia à cisplatina [84], em que o paciente apresentava aumento na expressão de CD63. Considerando exclusivamente a carboplatina, dois estudos avaliaram 0 potencial do BAT como ferramenta diagnóstica na avaliação de alergia à droga 
[88, 89]. Em um estudo de 2012, foi observada uma maior expressão de CD203c avaliada por meio do BAT em pacientes alérgicos à carboplatina quando comparado a pacientes tolerantes à droga [88]. Iwamoto et al. avaliaram a expressão de CD203c, realizando o BAT na véspera da exposição à carboplatina em pacientes até então tolerantes, e observaram relação entre o aumento da expressão da proteína e a ocorrência de reações de hipersensibilidade graves [89]. Ainda não há estudos disponíveis a respeito do comportamento de ambos marcadores de ativação basofílica, CD63 e CD203c, em pacientes alérgicos às platinas e sobre a aplicação do BAT na avaliação de pacientes submetidos à dessensibilização.

\subsection{Dessensibilização a medicamentos: definição e mecanismos}

As evidências demonstram que na prática médica, a maioria dos pacientes que apresenta reações de hipersensibilidade a medicamentos é classificada como alérgica e é privada de receber o tratamento mais adequado para sua enfermidade. A dessensibilização a medicamentos é abordagem alternativa, por meio da qual o paciente passa a tolerar a medicação que antes desencadeava reações potencialmente letais [90]. Este procedimento é tradicionalmente indicado em caso de reações de hipersensibilidade do tipo I [90]. Ele é dividido em etapas e possibilita a administração de doses terapêuticas do medicamento implicado na reação alérgica em um intervalo de tempo relativamente curto, em torno de 4 a 12 horas [91]. 
Ao contrário da imunoterapia alérgeno-específica, a dessensibilização ocasiona tolerância temporária ao alérgeno implicado na reação, sendo necessária a repetição do procedimento a cada administração do medicamento. Os mecanismos de ação da dessensibilização não são totalmente compreendidos, podendo abranger desde a indução de um estado hiporreativo de mastócitos específico para o antígeno usado na dessensibilização por meio da internalização de receptores FcદRI após exposição a concentrações baixas do antígeno [92], até prejuízo na desgranulação [93] e depleção de componentes de sinais de ativação da transdução, como a tirosino-quinase Syk [90, 94, 95]. Um estudo de 2011 sugeriu que na verdade ocorreria prejuízo na internalização do complexo lgEFcદRl durante a dessensibilização alérgeno-específica, fato que pode ser devido em parte à mobilidade dos complexos antígeno/lgE/FceRI e ao rearranjo na membrana celular [11, 93] (Figura 1). Por fim, também é estabelecido o papel da molécula Stat-6, transdutora de sinal e ativadora de transcrição, no processo de dessensibilização. Em estudo de 2005, o procedimento de dessensibilização de mastócitos in vitro não foi bem sucedido em camundongos deficientes em Stat-6 [94].

Embora dados a respeito do comportamento dos mastócitos frente à dessensibilização alérgeno-específica sejam conhecidos, o mesmo não pode ser dito a respeito dos basófilos e de seus conhecidos marcadores de ativação, CD63 e CD203c. 


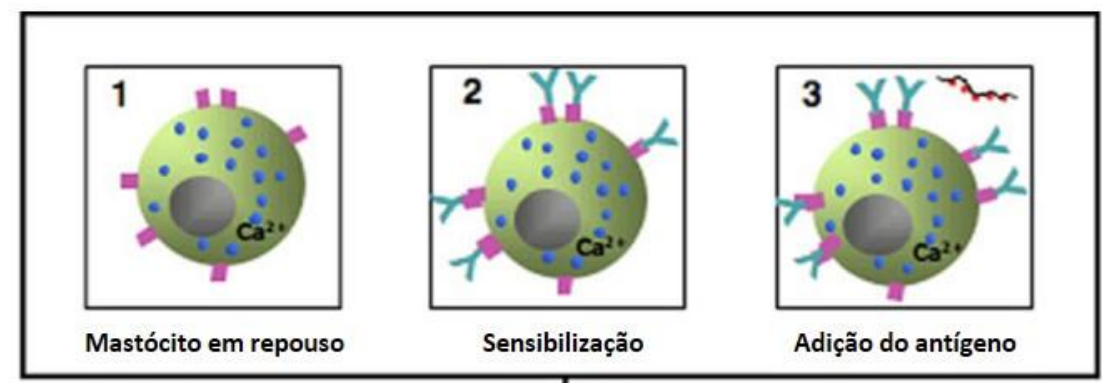

\section{Ativação}

(um complexo antígeno/IgE/FceRI é mostrado)
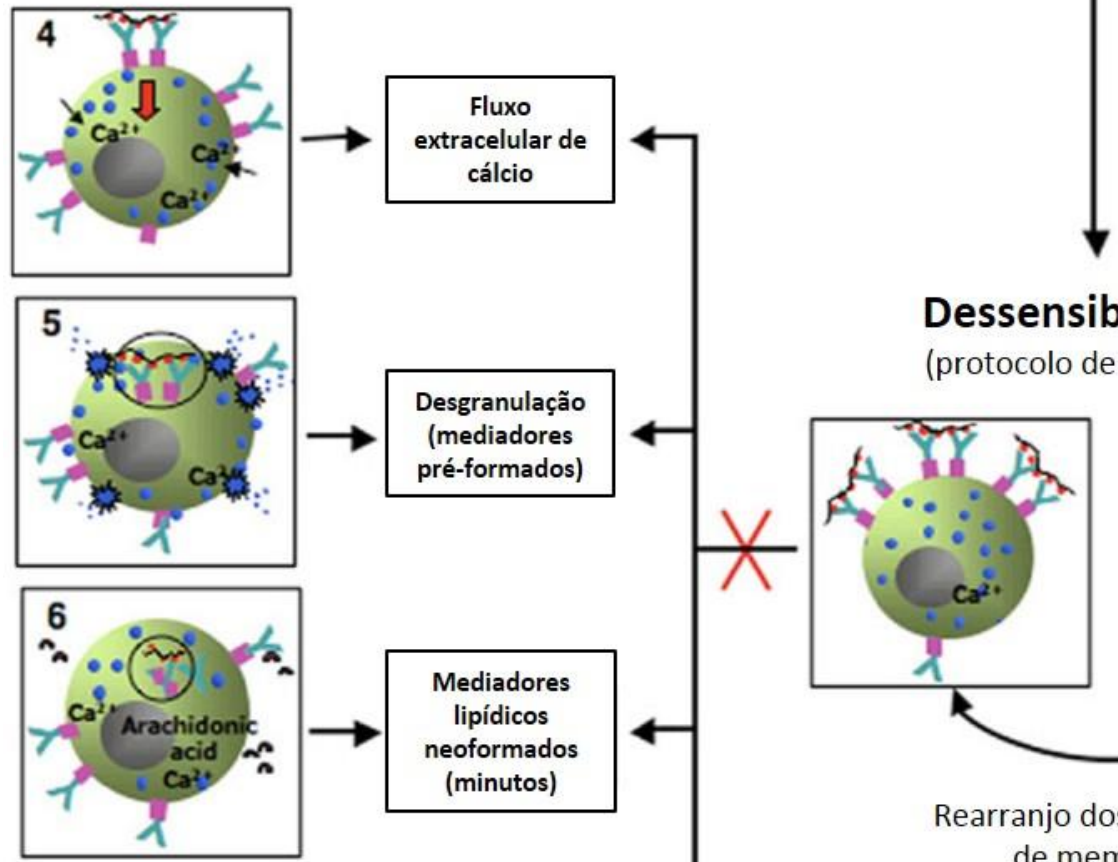

\section{Dessensibilização}

(protocolo de 11 passos)

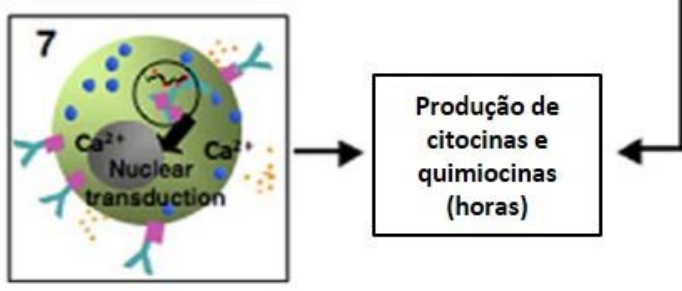

Receptor FceRI

Y IgE

Antigeno multivalente
- Mediadores pré-formados

A Mediadores lipídicos neoformados

citocinas e quimiocinas

Figura 1. Esquema simplificado ilustrando ativação e dessensibilização Adaptado da referência [11] 


\subsection{Dessensibilização a platinas}

A dessensibilização a platinas permite que pacientes com câncer sejam tratados com medicamentos de primeira escolha, diminuindo a morbidade e mortalidade da doença [96-98]. Os pacientes apresentariam aumento de sobrevida [99], alguns inclusive com chance de cura, e não necessitariam ser expostos a terapias de segunda linha, evitando assim efeitos adversos e falha terapêutica.

O grupo pioneiro na área de dessensibilização a medicamentos, chefiado pela Dra Mariana Castells, no Brigham and Women`s Hospital (BWH), em Boston, $[8,11,100-102]$ desenvolveu um programa seguro e que permite a reintrodução dos medicamentos envolvidos em anafilaxias, IgE mediadas ou não. O esquema de dessensibilização baseia-se na administração progressiva de pequenas doses da medicação que atuariam como estímulo inibitório, bloqueando a ativação celular [93]. Experimentos in vitro têm demonstrado os efeitos inibitórios da dessensibilização em mastócitos e basófilos, permitindo inclusive o aprimoramento do procedimento [93]. Atualmente, a equipe do BWH realiza cerca de seis procedimentos de dessensibilização a quimioterápicos e anticorpos monoclonais por dia.

Em 2008, o grupo publicou casuística com 413 casos de dessensibilização em pacientes oncológicos, demonstrando a segurança do protocolo desenvolvido e eficácia superior a 95\%; achados estes confirmados em estudo de 2016 avaliando 2177 dessensibilizações realizadas em 370 pacientes portadores de câncer, vasculites, doenças hematológicas e do tecido conectivo 
[8, 99]. Nessa casuística, 93\% dos pacientes ou não apresentaram reações, ou manifestaram apenas quadros leves [99]. Reações consideradas moderadas ou graves foram reportadas em $7 \%$ dos pacientes, porém as mesmas não resultaram na interrupção do tratamento. Não houve nenhum óbito relacionado aos procedimentos de dessensibilização [99, 101].

Em avaliação de 105 procedimentos de dessensibilização a anticorpos monoclonais, Brennan et al observaram uma incidência de $29 \%$ de reações de hipersensibilidade durante 0 procedimento, sendo a maioria também classificada como leve (90\%) [101]. Entretanto, reações graves também são relatadas e, caso não identificadas prontamente, podem levar a quadros clínicos que exigem intervenção médica emergencial. Hipotensão e insuficiência respiratória podem ocorrer e motivam a utilização de epinefrina intramuscular e a implementação de medidas de suporte ventilatório.

\subsection{BRCA 1 e 2}

Mutações germinativas deletérias nos genes supressores tumorais BRCA 1 e BRCA 2 relacionam-se à maior susceptibilidade aos cânceres de mama e ovário nas mulheres [103], e aos cânceres de próstata e mama nos homens [104, 105]. Tais mutações encontram-se presentes em cerca de $17 \%$ dos casos de neoplasias malignas de ovário e tubas uterinas e em menos de $10 \%$ dos casos de câncer de mama [103, 106].

A pesquisa destas mutações e aconselhamento genético estão indicados em pacientes nos quais se acredita haver uma predisposição hereditária aos 
cânceres de mama e/ou ovário. No caso de pacientes já portadores de neoplasia de mama ou ovário, a pesquisa complementa a investigação no sentido de determinar se a neoplasia faz parte de alguma síndrome genética, e ajuda a nortear o tratamento [107]. Pacientes portadores destas mutações apresentam resposta terapêutica superior com quimioterápicos do grupo das platinas [108] e frequentemente recebem múltiplos cursos de quimioterapia baseada nesta classe de agentes.

Recentemente, a mutação dos genes BRCA 1 e 2 foi identificada como um fator de risco independente para o desenvolvimento de reações de hipersensibilidade à carboplatina [106]. Em estudo de 2013, Moon et al. avaliaram retrospectivamente 87 pacientes portadoras de câncer de ovário, tubas uterinas e carcinoma peritoneal primário tratadas com carboplatina, observando uma prevalência de $21 \%$ de reações alérgicas à medicação. A maioria dos pacientes que apresentaram reações alérgicas à droga exibiam mutação nos genes BRCA 1 ou 2 (93\%) contra $50 \%$ das pacientes sem manifestação alérgica $(p<0,0001)$. Os autores também observaram correlação entre a presença da mutação e o surgimento mais precoce de reação de hipersensibilidade à carboplatina, contrariando a hipótese original de que tal população apresentaria maior incidência de reações alérgicas porque seria exposta ao quimioterápico um número maior de vezes (Figura 2, p=0,003).

A prevalência da mutação dos genes BRCA 1 e BRCA 2 nos pacientes alérgicos às platinas submetidos à dessensibilização ainda não foi avaliada. 


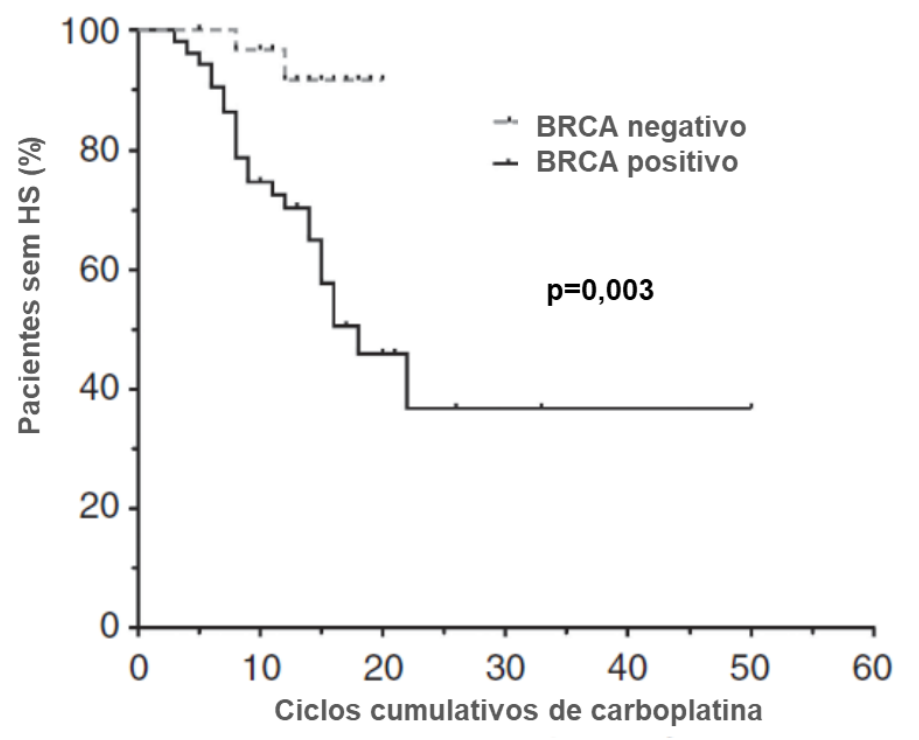

Figura 2. Análise Kaplan-Meier do risco de desenvolvimento de reações de hipersensibilidade à carboplatina em relação aos ciclos cumulativos de carboplatina. Os pacientes estão estratificados de acordo com a presença ou ausência da mutação BRCA 1/2 (adaptado de [106]).

Apesar dos estudos publicados sobre dessensibilização com quimioterápicos, esta terapia é inovadora e seus mecanismos de ação não estão completamente elucidados. A administração de medicamentos potencialmente letais para pacientes sensibilizados é uma abordagem pioneira de alto risco, que altera o paradigma atual de que reações alérgicas impedem a utilização de terapias de primeira linha. Estudos que avaliem os aspectos moleculares e genéticos envolvidos na dessensibilização serão esclarecedores e poderão identificar biomarcadores e potenciais alvos terapêuticos, permitindo assim que o procedimento se torne cada mais seguro e eficaz. 
2. HIPÓTESES 
O BAT pode ser um exame adicional na investigação de pacientes que apresentam reações de hipersensibilidade às platinas, auxiliando no diagnóstico e tratamento dos mesmos.

O aumento da expressão de CD63 e CD203c nos basófilos de pacientes submetidos regularmente ao processo de dessensibilização, após estimulação com carboplatina in vitro, pode predizer a ocorrência de reações durante 0 procedimento.

A positividade do BAT possivelmente associa-se ao aumento de triptase sérica nos pacientes que apresentam reações de hipersensibilidade durante o procedimento de dessensibilização ao quimioterápico.

A prevalência da mutação nos genes BRCA 1 e 2 é possivelmente maior nos pacientes alérgicos à carboplatina submetidos à dessensibilização e sua presença pode ter impacto no procedimento de dessensibilização. 
3. OBJETIVOS 


\subsection{Objetivo Geral}

- Avaliar o teste de ativação de basófilos, por meio da expressão das proteínas CD63 e CD203c, como biomarcador em pacientes alérgicos às platinas submetidos à dessensibilização.

\subsection{Objetivos Específicos}

- Determinar a sensibilidade e especificidade do teste de ativação de basófilos no diagnóstico de alergia a platinas.

- Analisar a evolução do teste de ativação de basófilos no transcorrer de sucessivas dessensibilizações.

- Correlacionar o teste de ativação de basófilos com a ocorrência de reações alérgicas durante o procedimento de dessensibilização.

- Correlacionar o teste de ativação de basófilos com os níveis de triptase durante o procedimento de dessensibilização em caso de nova reação clínica.

- Avaliar a prevalência da mutação dos genes BRCA 1 e 2 em população com história de hipersensibilidade imediata à carboplatina e seu impacto no procedimento de dessensibilização. 
4. MÉTODOS 


\subsection{Estudo BAT - realização de BAT e pesquisa de triptase sérica:}

\subsubsection{Casuística e delineamento}

Estudo prospectivo longitudinal realizado nos hospitais Brigham and Women`s Hospital (BWH) e Dana-Farber Cancer Institute (DFCl), filiados à Harvard Medical School em Boston, Massachusetts, EUA; e no Hospital das Clínicas da FMUSP, São Paulo, Brasil. O projeto foi submetido aos comitês de ética em pesquisa Partners Institutional Review Board (protocolos 13-288 e 2012P002275) e do Hospital das Clínicas (Plataforma Brasil: CAAE 22701913.6.0000.0068), e aprovado. Os pacientes que concordaram em participar, assinaram termo de consentimento livre e esclarecido e foram incluídos no estudo.

Foram selecionados pacientes portadores de neoplasias malignas submetidos à dessensibilização por história de alergia a quimioterápicos do grupo das platinas (carboplatina ou oxaliplatina). Todos os pacientes incluídos deveriam apresentar história prévia de hipersensibilidade imediata ao quimioterápico, considerada reação clínica durante ou até uma hora após a infusão do medicamento, e teste cutâneo de leitura imediata positivo para a platina implicada na reação.

Os pacientes foram encaminhados pelo oncologista responsável ao Ambulatório de Dessensibilização do BWH. Em uma primeira consulta de triagem, os doentes foram avaliados por residentes do programa de Alergia e Imunologia do BWH, que confirmaram o diagnóstico de reação de 
hipersensibilidade imediata e de sensibilização às platinas. Os testes cutâneos de punctura (prick test) foram realizados na superfície anterior do antebraço utilizando-se uma gota do quimioterápico nas concentrações de $10 \mathrm{mg} / \mathrm{ml}$ de carboplatina ou $5 \mathrm{mg} / \mathrm{ml}$ de oxaliplatina. Os testes intradérmicos foram realizados com volume injetado de $0,03 \mathrm{ml}$ na superfície anterior do antebraço, nas concentrações de $1 \mathrm{mg} / \mathrm{ml}$ e $10 \mathrm{mg} / \mathrm{ml}$ (caso negativo com $1 \mathrm{mg} / \mathrm{ml}$ ) de carboplatina, e $0,5 \mathrm{mg} / \mathrm{ml}$ e $5 \mathrm{mg} / \mathrm{ml}$ (caso negativo com $0,5 \mathrm{mg} / \mathrm{ml}$ ) de oxaliplatina. A leitura dos testes foi realizada após 20 minutos e foram considerados testes de punctura positivos aqueles que desencadearam pápula com diâmetro superior a no mínimo $3 \mathrm{~mm}$ daquele produzido pelo controle negativo (diluente). Histamina $(10 \mathrm{mg} / \mathrm{mL}$ ) foi utilizada como controle positivo do teste de punctura. No caso dos testes intradérmicos, foram considerados positivos aqueles que desencadearam pápula de diâmetro superior a no mínimo $3 \mathrm{~mm}$ daquele produzido pela injeção inicial e superior à pápula desencadeada pela solução salina (controle negativo). Os pacientes que apresentavam rinite alérgica, asma alérgica ou dermatite atópica e pesquisa positiva de lgE específica para aeroalérgenos (teste cutâneo de leitura imediata ou lgE sérica) foram considerados atópicos.

Uma vez avaliados os riscos e indicada a dessensibilização pelo médico assistente responsável, o procedimento foi programado e realizado no DFCl.

Foram utilizados como critérios de exclusão:

- Utilização crônica ou recente (últimos 15 dias) de corticosteroides sistêmicos

- Citopenia (anemia, plaquetopenia ou leucopenia) grave 
- Contraindicação à dessensibilização (doenças cardiopulmonares avançadas)

- História de reação de hipersensibilidade imediata prévia desencadeada por outra etiologia, que não o quimioterápico

A periodicidade da administração do quimioterápico seguiu consensos oncológicos previamente estabelecidos [32, 109], ocorrendo em geral a cada três ou quatro semanas [8]. Em cada ciclo de administração da medicação quimioterápica, o procedimento de dessensibilização foi repetido. As amostras de sangue dos doentes foram obtidas antes da realização da dessensibilização e da administração de medicações profiláticas (anti-histamínicos e corticosteroides). O BAT foi realizado em pelo menos um ciclo de dessensibilização nos pacientes selecionados.

Foram formados dois grupos controles:

Controle 1- pacientes oncológicos, tolerantes às platinas e em tratamento no DFCl, que haviam recebido no mínimo 8 infusões de carboplatina. O BAT foi realizado em duas ocasiões nesse grupo de pacientes.

Controle 2- voluntários sadios que nunca haviam se exposto aos quimioterápicos do grupo das platinas e que se dispuseram a doar uma amostra de sangue para realização do BAT. O BAT foi realizado em duas ocasiões nesse grupo de pacientes. 


\subsubsection{Classificação das reações de hipersensibilidade}

As reações de hipersensibilidade que motivaram a indicação da dessensibilização assim como aquelas apresentadas pelos pacientes durante 0 procedimento foram classificadas de acordo com o sistema de Brown [110], presente na Tabela 1.

Tabela 1. Classificação das reações de hipersensibilidade imediata

\begin{tabular}{ll}
\hline Grau & Definido por \\
\hline 1- Leve & $\begin{array}{l}\text { Eritema generalizado, urticária, edema periorbitário ou } \\
\text { angioedema }\end{array}$ \\
\hline 2- Moderada & $\begin{array}{l}\text { Dispneia, estridor, sibilância, náuseas, vômitos, tontura (pré- } \\
\text { síncope), diaforese, opressão torácica / laringe ou dor abdominal }\end{array}$ \\
3- Grave & $\begin{array}{l}\text { Cianose ou } \mathrm{SpO}_{2} \leq 92 \% \text {, hipotensão (PAS }<90 \mathrm{mmHg} \text { em adultos), } \\
\text { confusão mental, colapso, perda de consciência ou incontinência }\end{array}$ \\
\hline $\begin{array}{l}\mathrm{SpO}_{2}: \text { saturação periférica de oxigênio; } \mathrm{PAS} \text { : pressão arterial sistólica. Adaptado da referência } \\
\text { [110]. }\end{array}$
\end{tabular}

\subsubsection{Protocolo de dessensibilização}

Foi utilizado o protocolo de dessensibilização padronizado no Programa de Dessensibilização do BWH [8]. O protocolo utiliza três ou quatro concentrações crescentes do medicamento que desencadeou a reação de hipersensibilidade imediata e é baseado em 12 a 16 etapas. Inicia-se com 1/50.000 da dose final do medicamento e prossegue-se dobrando a dose a 
cada 15 minutos (Tabela 2). O procedimento é realizado de forma a permitir que ao seu término o paciente tenha recebido a dose total do medicamento. 
Tabela 2. Exemplo de protocolo de dessensibilização a medicamentos - 3 soluções e 12 etapas

\begin{tabular}{|c|c|c|c|c|c|}
\hline Solução & \multicolumn{2}{|l|}{ Volume } & \multicolumn{2}{|c|}{$\begin{array}{l}\text { Concentração da } \\
\text { Solução (mg/ml) }\end{array}$} & $\begin{array}{c}\text { Dose Total em Cada } \\
\text { Solução (mg) }\end{array}$ \\
\hline$A$ & $250 \mathrm{ml}$ & & 0,02 & & 5 \\
\hline B & $250 \mathrm{ml}$ & & 0,2 & & 50 \\
\hline$C$ & $250 \mathrm{ml}$ & & 2 & & 500 \\
\hline Etapa & Solução & $\begin{array}{c}\text { Taxa } \\
(\mathrm{ml} / \mathrm{h})\end{array}$ & $\begin{array}{c}\text { Tempo } \\
\text { (minutos) }\end{array}$ & $\begin{array}{c}\text { Dose } \\
\text { administrada } \\
\text { (mg) }\end{array}$ & $\begin{array}{c}\text { Dose } \\
\text { administrada } \\
\text { acumulada }(\mathrm{mg})\end{array}$ \\
\hline 1 & $A$ & 2 & 15 & 0,01 & 0,01 \\
\hline 2 & $A$ & 5 & 15 & 0,025 & 0,035 \\
\hline 3 & $A$ & 10 & 15 & 0,05 & 0,085 \\
\hline 4 & $A$ & 20 & 15 & 0.1 & 0,185 \\
\hline 5 & B & 5 & 15 & 0,25 & 0,435 \\
\hline 6 & B & 10 & 15 & 0,5 & 0,935 \\
\hline 7 & $B$ & 20 & 15 & 1 & 1,935 \\
\hline 8 & B & 40 & 15 & 2 & 3,935 \\
\hline 9 & C & 10 & 15 & 5 & 8,935 \\
\hline 10 & C & 20 & 15 & 10 & 18,935 \\
\hline 11 & $C$ & 40 & 15 & 20 & 38,935 \\
\hline 12 & C & 75 & 184,4 & 461,065 & 500 \\
\hline
\end{tabular}




\subsubsection{Teste de ativação de basófilos (BAT)}

O BAT foi realizado nos pacientes submetidos à dessensibilização e nos pacientes dos grupos controles. A coleta da amostra de sangue foi realizada antes da administração do quimioterápico e de eventuais medicamentos profiláticos e o BAT teve por objetivo a análise do grau de ativação dos basófilos por meio da expressão de CD63 e de CD203c.

O sangue foi coletado em tubos a vácuo contendo heparina e o ensaio foi executado em até 4 horas após a coleta. Foram adicionados em cada tudo de

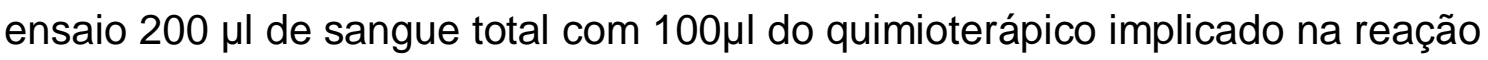
na maior concentração padronizada (Tabela 3). A maior concentração (500 $\mu \mathrm{g} / \mathrm{ml}$ ) mostrou melhores sensibilidade e reprodutibilidade, e a mesma especificidade das demais concentrações. Desta maneira, todos os resultados apresentados no estudo são relacionados a experimentos realizados com a maior concentração do quimioterápico.

Como controle positivo do ensaio, foi utilizado um tubo com $200 \mu \mathrm{l}$ de sangue total, $100 \mu l$ de quimioterápico na maior concentração padronizada e $3 \mu \mathrm{l}$ de anti-lgE (Biolegend). Como controle negativo foi utilizado tubo com adição de $200 \mu \mathrm{l}$ de sangue total e $100 \mu \mathrm{l}$ de solução salina. Os tubos foram incubados por 45 minutos em banho-maria (Fisher Scientific Isotemp 2L 240V Water Bath), na temperatura de $37^{\circ} \mathrm{C}$. Ao término da estimulação com o quimioterápico, as amostras foram mantidas a $4^{\circ} \mathrm{C}$, ao abrigo da luz, durante 30 minutos com a adição de 2,5ul dos seguintes anticorpos: anti-CD123 conjugado com aloficocianina (APC-Biolegend), anti-HLADR conjugado com 
isotiocianato de fluoresceína (FITC-Biolegend), anti-CD41 conjugado com isotiocianato de fluoresceína (FITC-Biolegend), anti-CD63 conjugado com ficoeritrina (PE-Biolegend) e anti-CD203c conjugado com Brilliant Violet (BVBiolegend).

Após os 30 minutos de marcação, os eritrócitos foram retirados por meio da adição de $3 \mathrm{ml}$ de solução de lise (Lysis Solution - Biolegend), com tempo de espera de 15 minutos e centrifugação durante 5 minutos (Beckman GPR Centrifuge). Posteriormente, as células foram lavadas por duas vezes com $3 \mathrm{ml}$ de solução tampão para citometria de fluxo (FACS Buffer solution), suspendidas novamente com $300 \mu \mathrm{l}$ da mesma solução e analisadas no citômetro de fluxo (Canto II, Becton-Dickinson BD, San Jose, California, EUA). A solução tampão (FACS Buffer solution) foi obtida misturando-se $500 \mathrm{ml}$ de tampão fosfato-salino (Phosphate Buffered Saline - PBS) com 2,5g de albumina bovina sérica (Bovine Serum Albumin - BSA - Sigma Aldrich $\circledast$ ), submetendo a mistura à homogeneização por meio de agitador magnético (Corning PC-520 PC520 Hot Plate Magnetic Stirrer) por 30 minutos e posterior filtragem. A solução tampão fosfato-salino (PBS) é obtida pela mistura de 1 litro de água destilada com 1 envelope de tampão fosfato-salino (Sigma Aldrich®).

A população de basófilos foi identificada pela expressão de CD123 (APC) e ausência de expressão de HLA-DR (FITC) e CD41 (FITC). Os basófilos expressam CD123 que é a cadeia alfa do receptor para IL-3 e normalmente não expressam a molécula do HLA. Utilizando-se este método, células dendríticas (CD123+ HLADR+) e basófilos com plaquetas aderidas (CD41+) foram excluídos da análise de ativação. As expressões de CD63 e CD203c, 
marcadores de ativação celular, foram analisadas dentro desta população. A aquisição de dados foi efetuada baseando-se na análise de pelo menos 100 basófilos.

Os resultados da ativação de basófilos foram expressos em percentagem (\%) das células marcadas pelos anticorpos e por meio da média geométrica da intensidade da fluorescência (gMFI) apresentada pelas células. Os resultados da citometria foram analisados utilizando-se o programa FlowJo versão 8.1 (TreeStar, Ashland, Ore). O BAT foi considerado positivo em caso de aumento de pelo menos duas vezes na expressão de CD63 ou CD203c após estímulo com a platina, em concentração padronizada (carboplatina $500 \mu \mathrm{g} / \mathrm{ml}$ e oxaliplatina $500 \mu \mathrm{g} / \mathrm{ml}$ ), comparado com o controle negativo, representando um índice de estimulação (gMFI platina / gMFI salina) $\geq 2$.

Tabela 3. Concentrações seriadas de carboplatina e oxaliplatina utilizadas no teste de ativação de basófilos

\begin{tabular}{ccc}
\hline $\begin{array}{c}\text { Concentrações de } \\
\text { carboplatina } / \\
\text { oxaliplatina }(\mu \mathrm{g} / \mathrm{ml})\end{array}$ & $\begin{array}{c}\text { Solução } \\
(\mu \mathrm{l})\end{array}$ & $\begin{array}{c}\text { Soro Fisiológico } \\
(\mu \mathrm{l})\end{array}$ \\
\hline 500 & 150 (solução mãe) & 850 \\
\hline 50 & 100 (solução de 500) & 900 \\
5 & 100 (solução de 50) & 900 \\
0,5 & 100 (solução de 5) & 900 \\
\hline
\end{tabular}

Solução mãe de carboplatina / oxaliplatina: $10 \mathrm{mg} / \mathrm{ml}$ 


\subsubsection{Dosagem sérica de triptase}

A dosagem sérica de triptase foi realizada nos pacientes antes e após a dessensibilização e durante eventual reação durante o procedimento. A triptase total foi dosada por método fluoroimunoenzimático (CAP System, Phadia). O método de detecção da triptase dosa concentrações de 1 a $200 \mu \mathrm{g} / \mathrm{L}$ e valores superiores a $11,5 \mu \mathrm{g} / \mathrm{L}$ são considerados anormais.

\subsection{Estudo BRCA - análise de prevalência da mutação dos genes BRCA} $1 / 2$

Foi realizada análise retrospectiva de 239 registros consecutivos de pacientes portadoras de neoplasias malignas ginecológicas, tratadas no DFCl e submetidas à dessensibilização à carboplatina no Brigham and Women`s Hospital, entre janeiro de 2011 e outubro de 2015, para estimar a prevalência da mutação dos genes BRCA 1/2. Dentre os registros, foram selecionadas as pacientes que haviam sido investigadas para a presença da mutação dos genes BRCA 1/2 ( $n=138)$.

O estudo foi aprovado pelo comitê de ética em pesquisa Partners Institutional Review Board (protocolo 13-288). As pacientes assinaram termo de consentimento livre e esclarecido. 


\subsubsection{Pesquisa da mutação dos genes BRCA 1 e 2}

A pesquisa da mutação dos genes BRCA 1 e 2 foi realizada por meio do painel de teste OvaNext (AmbryGenetics ${ }^{\mathrm{TM}}$ ) por sequenciamento de nova geração (NGS) ou pelo BRACAnalysis ${ }^{\circledR}\left(\right.$ Myriad $\left.^{\circledR}\right)$, pela técnica de PCR alelo específico (AS).

\subsection{Análise Estatística}

As variáveis contínuas foram expressas como valores absolutos, porcentagens relativas ou média \pm desvio padrão (DP). Comparação entre mais de dois grupos foi realizada por meio do ANOVA, seguido do teste de Bonferroni; e comparações entre dois grupos foram realizadas com o teste $t$ de Student. Variáveis categóricas foram apresentadas como números e percentuais, analisados pelo teste de qui-quadrado e o teste exato de Fisher. A análise foi realizada com o software GraphPad Prism (versão 6.0a) e valor de $p$ $<0,05$ foi considerado estatisticamente significante. 
5. RESULTADOS 


\subsection{Estudo BAT - realização de BAT e pesquisa de triptase sérica:}

\subsubsection{Caracterização das amostras}

Foram selecionadas 15 pacientes alérgicas às platinas para a realização do BAT antes do procedimento de dessensibilização, todas do sexo feminino. A caracterização geral das pacientes alérgicas e das reações, além dos resultados de testes cutâneos e valores de triptase durante a reação inicial (quando presentes em prontuário) encontram-se na Tabela 4. O delineamento geral da estratificação de risco e dos procedimentos aos quais as pacientes alérgicas foram submetidas pode ser observado na Figura 3.

De maneira geral, os grupos alérgico e controle 1 (tolerantes às platinas) foram bastante similares, exceto pela maior frequência de atopia no grupo alérgico ( $p=0,02 ;$ Tabela 5). A média de idade do grupo de pacientes alérgicas foi 58 anos, variando de 25 a 74 anos. A média etária do grupo controle 1 foi 56,5 anos, variando de 36 a 71 anos, enquanto que a média etária do grupo controle 2 (nunca expostos às platinas) foi 40,2 , variando de 30 a 47 anos. No grupo controle $1,83,3 \%$ dos pacientes eram do sexo feminino, enquanto no grupo controle 2, 66,7\% dos voluntários eram mulheres.

Com relação aos tipos de neoplasias malignas, no grupo de pacientes alérgicas, onze pacientes apresentavam diagnóstico de câncer de ovário, uma de mama e três de sigmoide. A carboplatina foi a droga de escolha em doze doentes $(80 \%)$ e três pacientes receberam oxaliplatina (20\%). A média de 
número de ciclos de carboplatina antes da ocorrência da reação inicial foi de 9,9 ciclos, e de 9 exposições para a oxaliplatina.

No grupo controle 1, quatro pacientes apresentavam câncer de ovário, uma de seios etmoidais e um de orofaringe. A carboplatina foi utilizada em todos os pacientes deste grupo, sendo a média do número de exposições de 18,2. Dois pacientes deste grupo também apresentavam exposições prévias à cisplatina (4 e 6 exposições).

No grupo das pacientes alérgicas, as reações iniciais foram classificadas como grau 1 em 13,3\% das pacientes, grau 2 em $26,6 \%$ e mais da metade das doentes apresentaram reações iniciais grau $3(60,0 \%)$. O valor de triptase quando da reação inicial pôde ser recuperado do prontuário de três pacientes: $39,2 \mu \mathrm{g} / \mathrm{L}, 16,3 \mu \mathrm{g} / \mathrm{L}$ e $4,9 \mu \mathrm{g} / \mathrm{L}$. Todas as doentes apresentaram testes cutâneos de leitura imediata positivos, utilizando-se as diluições de quimioterápico para teste de punctura ou teste intradérmico padronizadas na literatura [102] (Tabela 4). A maioria das pacientes alérgicas a carboplatina apresentaram testes cutâneos positivos realizando-se prick na concentração de $10 \mathrm{mg} / \mathrm{ml}$ ou intradérmico na concentração de $1 \mathrm{mg} / \mathrm{ml}$ (91,6\%), enquanto que todas as alérgicas à oxaliplatina apresentaram testes positivos por meio do prick com a diluição de $5 \mathrm{mg} / \mathrm{ml}$ ou do intradérmico na menor diluição $(0,5$ $\mathrm{mg} / \mathrm{ml}$ ) (Tabela 4). 
Tabela 4. Estudo BAT: caracterização geral das pacientes alérgicas e das reações de hipersensibilidade imediata

\begin{tabular}{|c|c|c|c|c|c|c|c|c|}
\hline $\begin{array}{c}\text { Número } \\
\text { do } \\
\text { protocolo }\end{array}$ & Idade & $\begin{array}{c}\text { Tipo de } \\
\text { neoplasia }\end{array}$ & $\begin{array}{l}\text { Mutação } \\
\text { BRCA 1/2 }\end{array}$ & $\begin{array}{l}\text { Medicação } \\
\text { implicada }\end{array}$ & $\begin{array}{l}\text { Número do } \\
\text { ciclo (reação } \\
\text { inicial) }\end{array}$ & $\begin{array}{l}\text { Grau da } \\
\text { reação* }\end{array}$ & $\begin{array}{c}\text { Triptase reação } \\
\text { inicial }(V R \leq 11,5 \\
\mu \mathrm{g} / \mathrm{L})\end{array}$ & $\begin{array}{l}\text { Positividade } \\
\text { do teste } \\
\text { cutâneo }\end{array}$ \\
\hline 1 & 57 & Ovário & - & Carboplatina & 14 & 3 & 39,2 & ID $1 \mathrm{mg} / \mathrm{ml}$ \\
\hline 2 & 59 & Ovário & + & Carboplatina & 11 & 2 & 4,9 & ID $1 \mathrm{mg} / \mathrm{ml}$ \\
\hline 3 & 60 & Ovário & - & Carboplatina & 5 & 2 & ND & ID $1 \mathrm{mg} / \mathrm{ml}$ \\
\hline 4 & 59 & Ovário & + & Carboplatina & 9 & 1 & ND & ID $1 \mathrm{mg} / \mathrm{ml}$ \\
\hline 5 & 58 & Ovário & + & Carboplatina & 5 & 3 & ND & ID $1 \mathrm{mg} / \mathrm{ml}$ \\
\hline 6 & 49 & Ovário & - & Carboplatina & 20 & 1 & ND & ID $1 \mathrm{mg} / \mathrm{ml}$ \\
\hline 7 & 74 & Ovário & - & Carboplatina & 8 & 3 & ND & ID $1 \mathrm{mg} / \mathrm{ml}$ \\
\hline 8 & 61 & Ovário & NR & Carboplatina & 5 & 3 & ND & ID $1 \mathrm{mg} / \mathrm{ml}$ \\
\hline 9 & 62 & Ovário & + & Carboplatina & 8 & 2 & ND & ID $1 \mathrm{mg} / \mathrm{ml}$ \\
\hline 10 & 60 & Ovário & - & Carboplatina & 12 & 3 & ND & Prick $10 \mathrm{mg} / \mathrm{ml}$ \\
\hline 11 & 68 & Ovário & NR & Carboplatina & 14 & 3 & 16,3 & ID $1 \mathrm{mg} / \mathrm{ml}$ \\
\hline 12 & 39 & Mama & NR & Carboplatina & 8 & 2 & ND & ID $10 \mathrm{mg} / \mathrm{ml}$ \\
\hline 13 & 73 & Cólon & NR & Oxaliplatina & 13 & 3 & ND & Prick 5mg/ml \\
\hline 14 & 66 & Cólon & NR & Oxaliplatina & 6 & 3 & ND & ID $0,5 \mathrm{mg} / \mathrm{ml}$ \\
\hline 15 & 25 & Cólon & NR & Oxaliplatina & 8 & 3 & ND & Prick 5mg/ml \\
\hline
\end{tabular}

NR: não realizado; ND: não disponível; ID: intradérmico; VR: valor de referência

* de acordo com a classificação das reações de hipersensibilidade imediata de Brown [110] 
Tabela 5. Dados gerais dos três grupos do estudo BAT: pacientes alérgicas, controle 1 e controle 2

\begin{tabular}{|c|c|c|c|c|}
\hline & $\begin{array}{l}\text { Pacientes } \\
\text { alérgicas }\end{array}$ & $\begin{array}{c}\text { Pacientes } \\
\text { tolerantes } \\
\text { (Grupo } \\
\text { controle 1) }\end{array}$ & Valor $p^{\#}$ & $\begin{array}{c}\text { Participantes } \\
\text { saudáveis } \\
\text { (Grupo } \\
\text { controle 2) }\end{array}$ \\
\hline $\mathrm{N}$ & 15 & 6 & & 6 \\
\hline Carboplatina & 12 & 6 & & - \\
\hline Oxaliplatina & 3 & - & & - \\
\hline $\begin{array}{l}\text { Idade, } \\
\text { média (DP) }\end{array}$ & $58(12,6)$ & $56,5(12,6)$ & NS & $40,2(9,6)$ \\
\hline $\begin{array}{l}\text { Mulheres, } \\
\text { n (\%) }\end{array}$ & $15(100)$ & $5(83,3)$ & NS & $4(66,7)$ \\
\hline $\begin{array}{l}\text { Câncer de ovário, } \\
\text { n (\%) }\end{array}$ & $11(73,3)$ & $4(66,7)$ & NS & - \\
\hline $\begin{array}{l}\text { Número de exposições } \\
\text { à carboplatina, } \\
\text { média (DP) }\end{array}$ & $9,9(4,5)$ & $18,2(18,7)$ * & NS & - \\
\hline $\begin{array}{l}\text { Número de exposições } \\
\text { à oxalipatina, } \\
\text { média (DP) }\end{array}$ & $9(3,6)$ & - & - & - \\
\hline $\begin{array}{l}\text { Mutação do BRCA } 1 / 2^{\dagger} \text {, } \\
\text { n (\%) }\end{array}$ & $4(44,4)$ & 0 & 0,05 & - \\
\hline Atopia, n (\%) & $8(53,3)$ & $0(0)$ & 0,02 & $5(83,3)$ \\
\hline
\end{tabular}

\# Comparação alérgicos versus grupo controle 1

* Dois pacientes também receberam cisplatina previamente (4 e 6 exposições)

†Total de pacientes avaliados: $\mathrm{n}=9$

NS: não significativo; DP: desvio padrão 


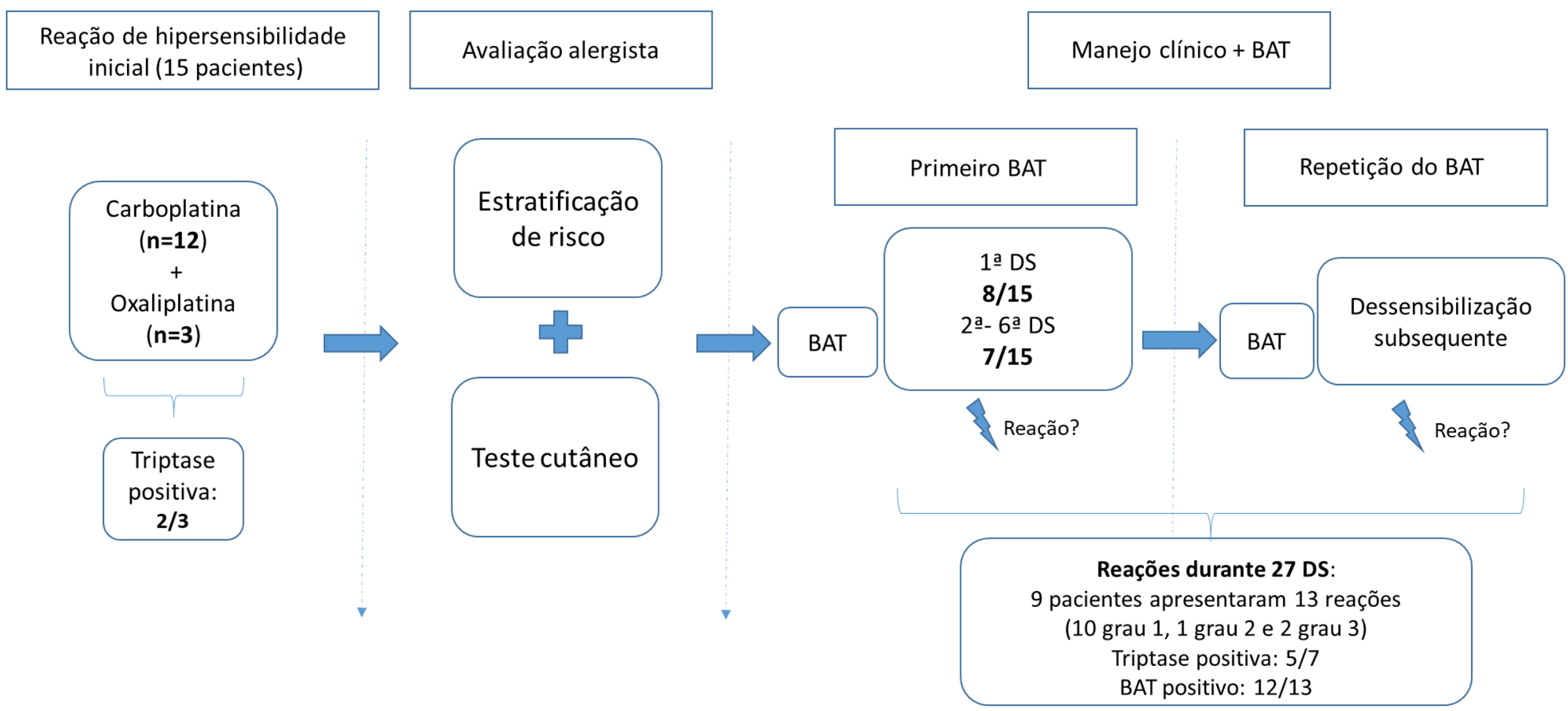

Figura 3. Delineamento geral do estudo BAT

DS: dessensibilização 


\subsubsection{Dessensibilizações e triptase}

Os dados relacionados ao procedimento de dessensibilização encontramse na Tabela 6. O tempo médio decorrido entre a última exposição ao quimioterápico e a dessensibilização foi de 30,2 dias. Uma paciente apresentou seis meses de intervalo entre a última aplicação e a dessensibilização. Os valores de triptase pré-dessensibilização, coletados no mesmo dia do procedimento, variaram de 3,7 a $13,9 \mu \mathrm{g} / \mathrm{L}$.

Durante a realização de 27 procedimentos de dessensibilização houve 13 reações (incidência de 48,1\%), sendo a maioria classificada como grau 1 ( $n=10 ; 76,9 \%$ ), com manifestações clínicas como eritema e prurido generalizados, eritema localizado em pés e prurido local, eritema em orelhas e palmas das mãos, urticária e flushing. Uma paciente apresentou reação grau 2, com flushing, náuseas, dor precordial e congestão nasal ( $n=1 ; 7,7 \%)$, e outras duas pacientes reação grau $3(n=2 ; 15,4 \%)$. Uma paciente apresentou prurido palmar, flushing, edema em mãos, vômitos e hipotensão, reação classificada como grau 3 ( $n=1 ; 7,7 \%)$. A paciente 11 também apresentou reação caracterizada como grau 3, com vômitos, urticária, flushing e queda de saturação durante a dessensibilização $(n=1 ; 7,7 \%)$. Também ocorreram reações caracterizadas isoladamente por parestesia em língua e aumento nos níveis tensionais associado à ansiedade, não consideradas para análise por não serem sugestivas de reações de hipersensibilidade. 
O valor de triptase sérica encontrava-se elevado em 5 de 7 reações em que foi mensurado, com valor médio foi de $32,38 \mu \mathrm{g} / \mathrm{L}$ (valor de referência: $\leq$ $11,5 \mu \mathrm{g} / \mathrm{L})$ (Tabela 6). 
Tabela 6. Desfecho da dessensibilização e resultados do BAT

\begin{tabular}{|c|c|c|c|c|c|c|c|}
\hline \multirow{2}{*}{$\begin{array}{c}\text { Número } \\
\text { do } \\
\text { Protocolo }\end{array}$} & \multirow{2}{*}{$\begin{array}{c}\text { Momento } \\
\text { do } \\
\text { BAT }\end{array}$} & \multirow{2}{*}{$\begin{array}{c}\text { Última } \\
\text { exposição } \\
\text { ao QT }\end{array}$} & \multirow{2}{*}{$\begin{array}{c}\text { Tripta } \\
\text { se } \\
\text { Basal }^{\star}\end{array}$} & \multirow{2}{*}{$\begin{array}{c}\text { Reações } \\
\text { durante DS } \\
\text { (Grau da } \\
\text { reação) }\end{array}$} & \multirow{2}{*}{$\begin{array}{c}\text { Triptase } \\
\text { durante } \\
\text { DS* }^{*}\end{array}$} & \multicolumn{2}{|c|}{ BAT } \\
\hline & & & & & & CD63 & CD203 \\
\hline \multirow[t]{2}{*}{1} & $1 \mathrm{DS}$ & 18 dias & 13,2 & $\operatorname{Sim}(1)$ & ND & + & + \\
\hline & $2 \mathrm{DS}$ & 27 dias & 13,9 & $\operatorname{Sim}(1)$ & 14,6 & + & + \\
\hline \multirow[t]{2}{*}{2} & 2 DS & 28 dias & ND & Não & ND & - & - \\
\hline & $5 \mathrm{DS}$ & 21 dias & ND & Não & ND & - & - \\
\hline \multirow[t]{2}{*}{3} & $5 \mathrm{DS}$ & 19 dias & ND & $\operatorname{Sim}(1)$ & ND & - & + \\
\hline & $6 \mathrm{DS}$ & 22 dias & ND & Não & ND & - & + \\
\hline \multirow[t]{2}{*}{4} & 2 DS & 19 dias & ND & Não & ND & - & - \\
\hline & 3 DS & 22 dias & ND & $\operatorname{Sim}(1)$ & ND & - & + \\
\hline \multirow[t]{5}{*}{5} & $1 \mathrm{DS}$ & 6 meses & ND & $\operatorname{Sim}(1)$ & ND & - & + \\
\hline & 3 DS & 21 dias & 6,2 & $\operatorname{Sim}(1)$ & ND & + & + \\
\hline & $4 \mathrm{DS}$ & 21 dias & 6,3 & $\operatorname{Sim}(3)$ & 56,2 & + & + \\
\hline & $5 \mathrm{DS}$ & 21 dias & ND & $\operatorname{Sim}(1)$ & 25,3 & + & + \\
\hline & $6 \mathrm{DS}$ & 21 dias & ND & Não & ND & + & + \\
\hline 6 & $4 \mathrm{DS}$ & 21 dias & ND & $\operatorname{Sim}(2)$ & 23 & + & + \\
\hline \multirow[t]{2}{*}{7} & $1 \mathrm{DS}$ & 27 dias & 10,9 & Não & 11,5 & - & - \\
\hline & 2 DS & 21 dias & 13,4 & Não & 10,9 & - & - \\
\hline 8 & 2 DS & 21 dias & 7,1 & $\operatorname{Sim}(1)$ & 42,8 & + & + \\
\hline \multirow[t]{2}{*}{9} & 3 DS & 52 dias & 4,3 & $\operatorname{Sim}(1)$ & 4,1 & - & - \\
\hline & $5 \mathrm{DS}$ & 25 dias & ND & Não & ND & - & - \\
\hline 10 & $1 \mathrm{DS}$ & 26 dias & 6,5 & Não & 16 & - & - \\
\hline 11 & $1 \mathrm{DS}$ & 21 dias & ND & $\operatorname{Sim}(3)$ & ND & + & + \\
\hline 12 & $1 \mathrm{DS}$ & 45 dias & ND & Não & ND & - & + \\
\hline \multirow[t]{2}{*}{13} & $1 \mathrm{DS}$ & 29 dias & ND & Não & ND & - & + \\
\hline & $2 \mathrm{DS}$ & 15 dias & ND & Não & ND & - & + \\
\hline 14 & $6 \mathrm{DS}$ & 19 dias & 5,0 & Não & 5,5 & - & + \\
\hline \multirow[t]{2}{*}{15} & $1 \mathrm{DS}$ & 21 dias & ND & $\operatorname{Sim}(1)$ & 5,2 & + & + \\
\hline & $2 \mathrm{DS}$ & 34 dias & 3,7 & Não & 2,5 & - & + \\
\hline
\end{tabular}

* Valor de referência $\leq 11,5 \mu \mathrm{g} / \mathrm{L}$

DS: dessensibilização; QT: quimioterápico; BAT: teste de ativação de basófilos; ND: não disponível. 


\subsubsection{Teste de Ativação de Basófilos (BAT)}

No total foram realizados 27 BAT no grupo de pacientes alérgicas, 6 no grupo controle 1 e 12 no grupo controle 2. Em oito doentes o BAT foi realizado na primeira dessensibilização, enquanto que sete pacientes já haviam se submetido ao procedimento anteriormente quando realizaram o teste (Figura 3).

O BAT apresentou positividade em 11 pacientes alérgicas $(n=11 ; 73,3 \%)$, como os exemplos presentes nas Figuras 4 e 5, com aumento de expressão de CD203c e CD63 em 11/15 (73,3\%) e 6/15 (40\%) pacientes, respectivamente. Os grupos controle 1 e 2 apresentaram testes negativos para ambos os marcadores de ativação de basófilos (Figuras 6 e 7). Exemplo de teste negativo do grupo controle 1 pode ser observado nas Figuras 8 e 9. Todas as amostras incubadas apenas com solução salina (controles negativos) não apresentaram aumento de expressão de CD63 e CD203c, e todos os controles positivos dos testes (anti-lgE + quimioterápico) apresentaram aumento de expressão dessas moléculas.

Com relação às reações iniciais, apenas uma dentre seis pacientes $(16,7 \%)$ com reações iniciais graus 1 e 2 apresentou aumento de expressão de CD63, comparado a 5 de $9(55,6 \%)$ com reações grau $3(p=0,07)$ (Tabelas 4 e 6). O BAT foi positivo em 12 de 13 reações ocorridas durante os procedimentos de dessensibilização (92,3\%), com expressão aumentada de CD63 em 9 reações $(69,2 \%)$ e de CD203c em 12 reações (92,3\%) (Tabelas 6, A1 e A2). Em 14 procedimentos de dessensibilização não houve reações, e nestes o BAT 
foi positivo em sete, com aumento na expressão de CD203c nos sete casos (50\%) e de CD63 em apenas um caso (7,1\%) (Tabelas 6, A1 e A2). Nas reações moderadas e graves (graus 2 e 3 ) ocorridas durante a dessensibilização $(n=3)$, tanto o CD63 quanto o CD203c apresentaram expressão elevada (Tabela 6). Em todas as reações de hipersensibilidade ocorridas durante a dessensibilização que se apresentaram com aumento de triptase sérica (> 11,5 $\mu \mathrm{g} / \mathrm{L})$ o BAT foi positivo $(n=5)$. Nestes casos, houve aumento da expressão tanto de CD63 quanto de CD203c (Tabela 6).

Análises subsequentes do BAT em diferentes cursos de dessensibilização nas pacientes submetidas ao procedimento em pelo menos duas ocasiões $(n=9)$, mostraram que o teste persistia positivo e em alguns casos com expressão ainda mais pronunciada de CD203c e CD63. A Figura 10 ilustra a evolução do comportamento do teste em uma paciente submetida a cinco procedimentos de dessensibilização, por meio da análise dos dois marcadores de ativação basofílica. Em uma paciente (Tabela 6, paciente 4), o BAT passou a ser positivo após a segunda dessensibilização, fato que foi coincidente com reação clinica durante a terceira dessensibilização. Nenhuma paciente com teste inicial positivo para algum marcador evoluiu com a negativação do BAT.

Nas Figuras 6 e 7 podemos observar a comparação da média do índice de estimulação dos grupos de pacientes alérgicas, controle 1 e controle 2 para os marcadores CD203c e CD63, respectivamente. Para o marcador CD203c, foi encontrada diferença estatisticamente significante entre o grupo de pacientes alérgicas e os dois grupos controle, $1(p=0,002)$ e $2(p=0,001)$. Para o CD63, 
também foi observada diferença estatisticamente significante entre os grupos de pacientes alérgicas e ambos os grupos controle, $1(p=0,02)$ e $2(p=0,01)$. 
CD 63

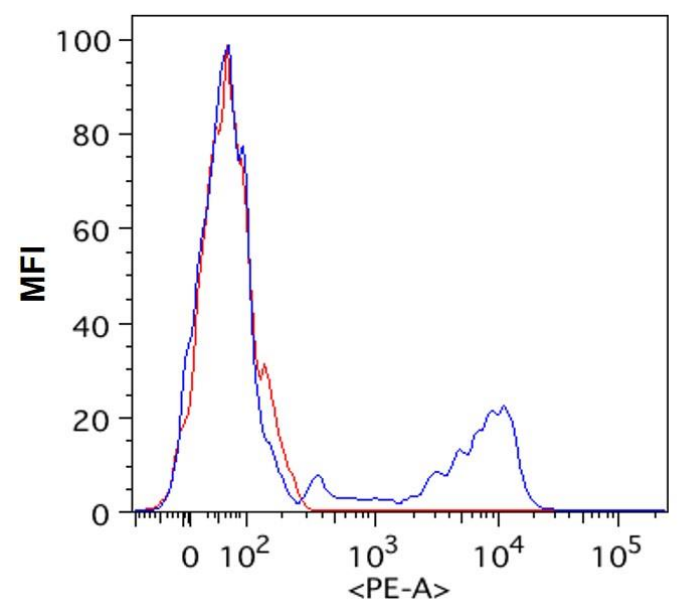

$\square$ 日 Specimen_001_Tube_004.fcs 0.77201

口曰 Specimen_001_Tube_003.fcs 1.5464 .2

gMFI

Linha azul: carboplatina

Linha vermelha: solução salina

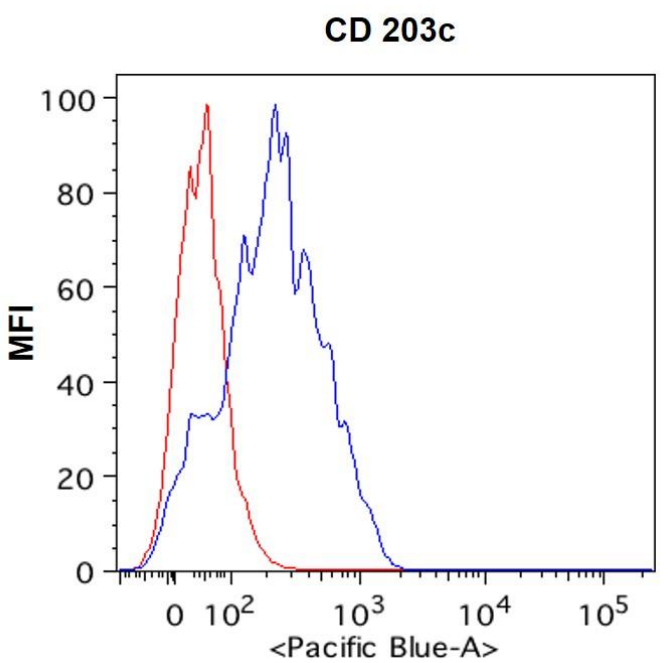

$\square$ 日 Specimen_001_Tube_004.fcs 0.77213 $\square$ 曰 Specimen_001_Tube_003.fcs $1.54 \quad 42.4$

gMFI

Figura 4. Exemplo de resultado positivo do BAT expresso por gMFI (média geométrica de intensidade de fluorescência): avaliação das expressões de CD63 e CD203c após incubação com solução salina (controle negativo) e carboplatina $500 \mu \mathrm{l} / \mathrm{ml}$ em paciente alérgica. 

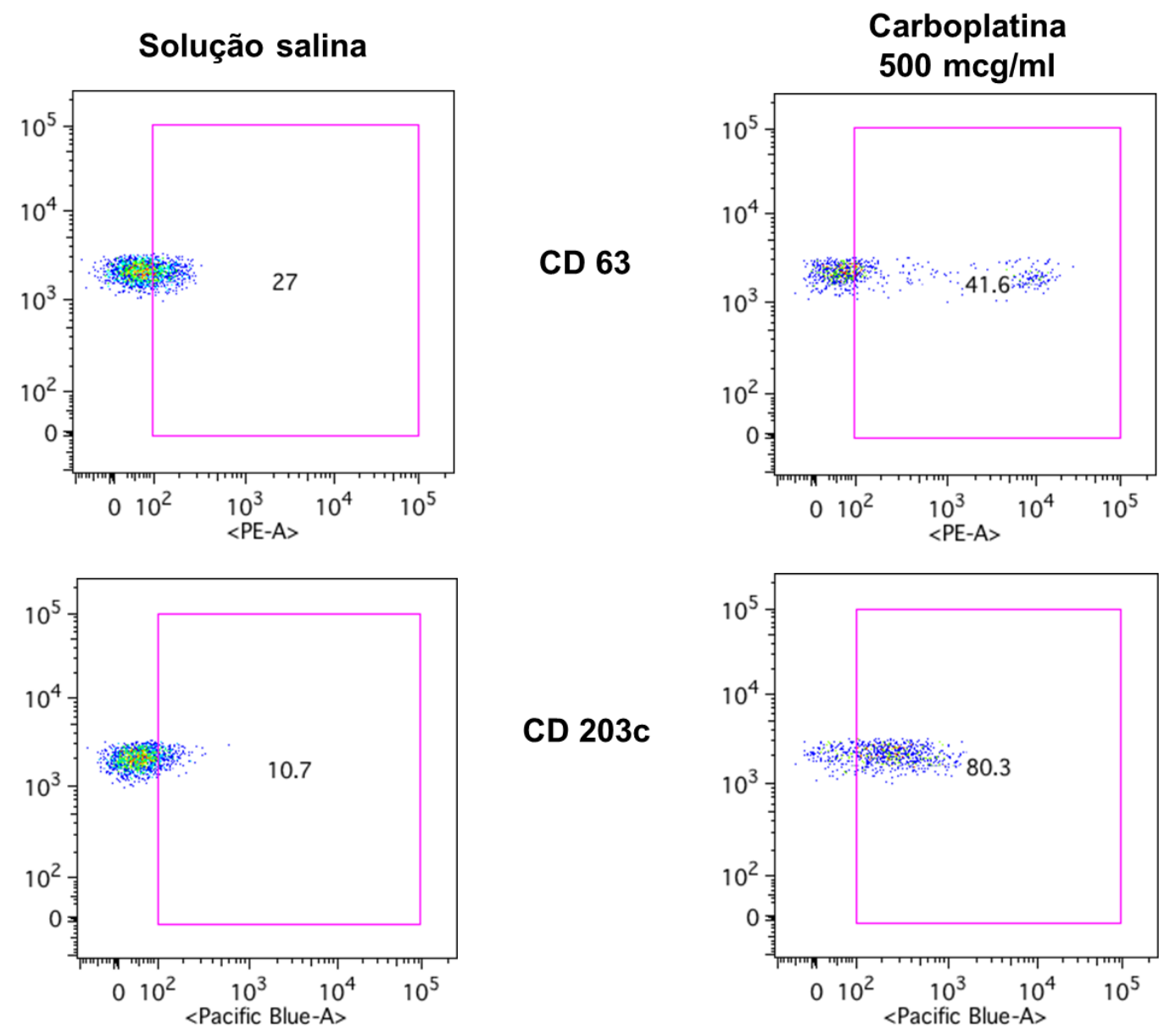

Figura 5. Exemplo de resultado positivo do BAT dado pelo percentual de células com expressão de CD63 e CD203c, após incubação com solução salina e carboplatina $500 \mu \mathrm{l} / \mathrm{ml}$ em paciente alérgica à carboplatina. 


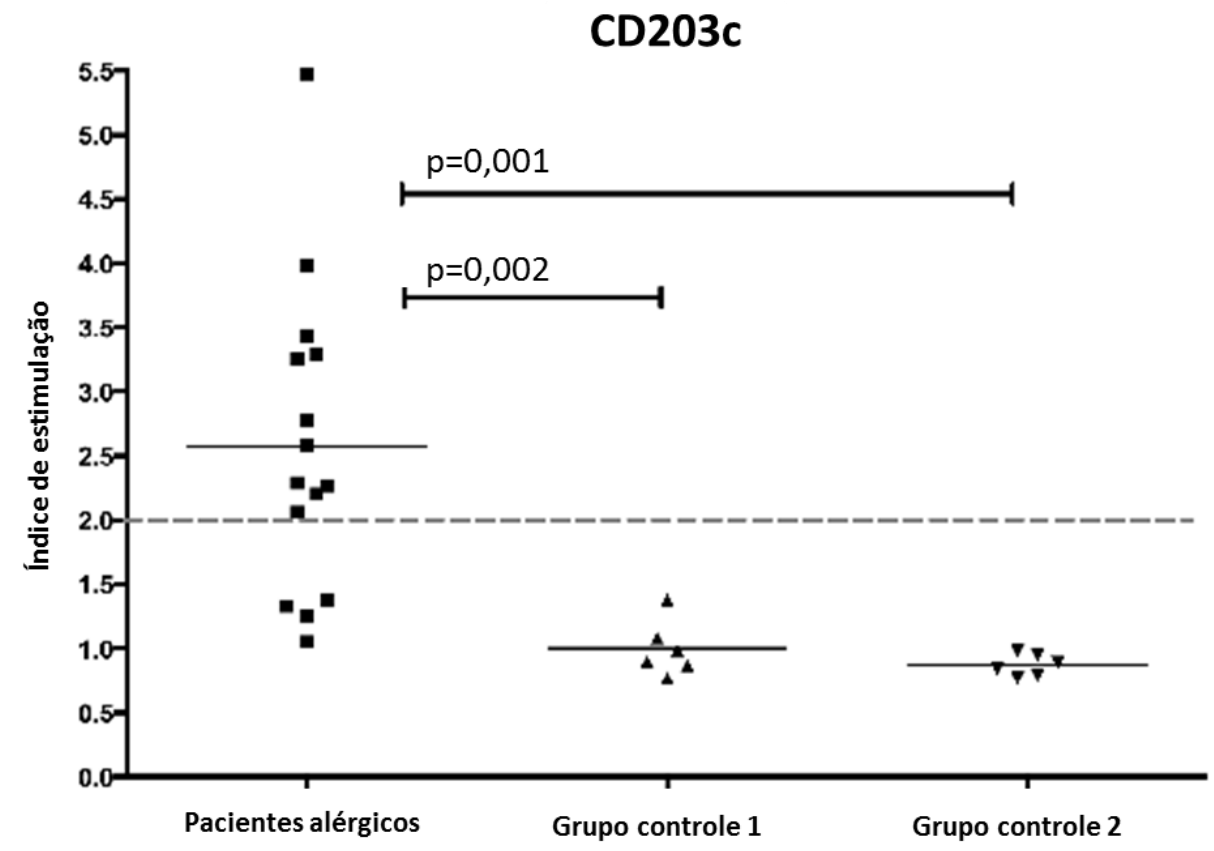

Figura 6. Expressão de CD203c nos grupos de pacientes alérgicas às platinas, grupo controle 1 (tolerantes à carboplatina) e grupo controle 2 (voluntários nunca expostos às platinas).

Índice de estimulação dos pacientes e média dos grupos (linha contínua). BAT com índice de estimulação $\geq 2$ foi considerado positivo (linha pontilhada).

Índice de estimulação: gMFI das células estimuladas com platina /gMFI das células estimuladas com salina. 


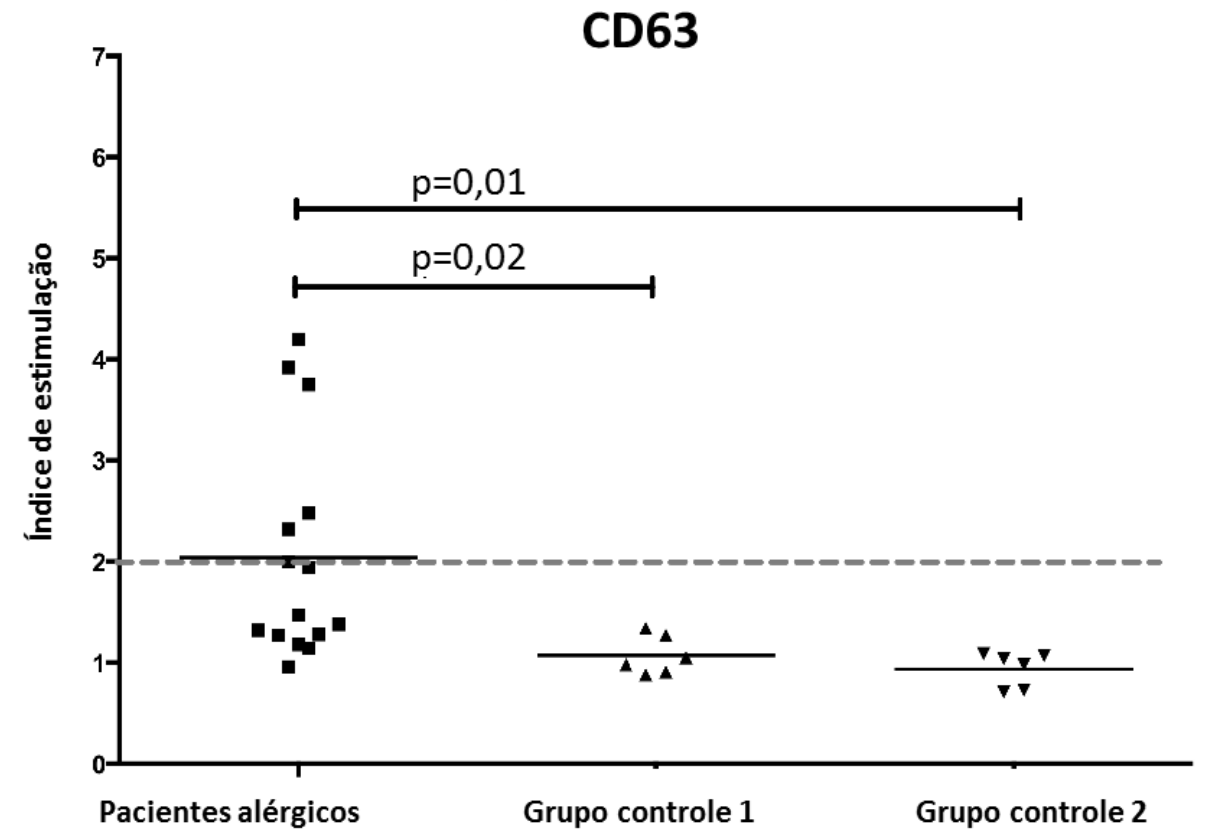

Figura 7. Expressão de CD63 nos grupos de pacientes alérgicas às platinas, grupo controle 1 (tolerantes à carboplatina) e grupo controle 2 (voluntários nunca expostos às platinas).

Índice de estimulação dos pacientes e média dos grupos (linha contínua). BAT com índice de estimulação $\geq 2$ foi considerado positivo (linha pontilhada).

Índice de estimulação: gMFI das células estimuladas com platina /gMFI das células estimuladas com salina. 
CD63

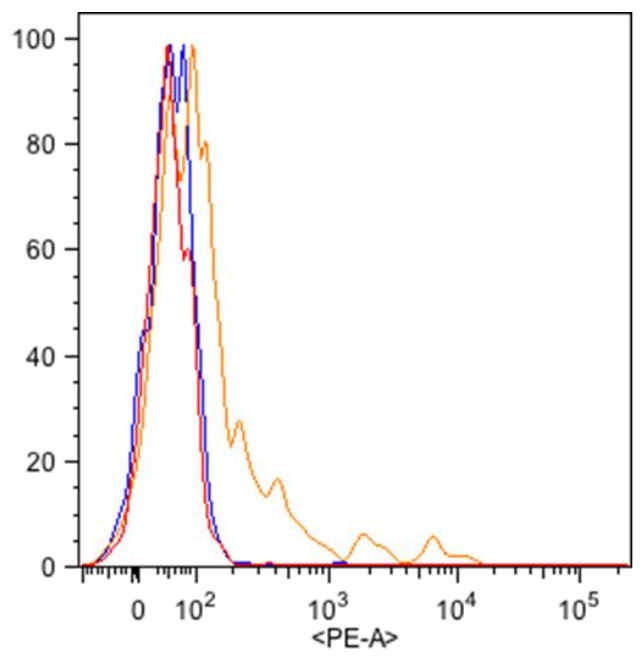

$\square$ 日pecimen_001_Saline.fcs 1.29 46.2

$\square$ Specimen_001_500.fcs 1.0148 .7

$\square$ 日 Specimen_001_antiige.fcs $0.82 \quad 121$
CD203c

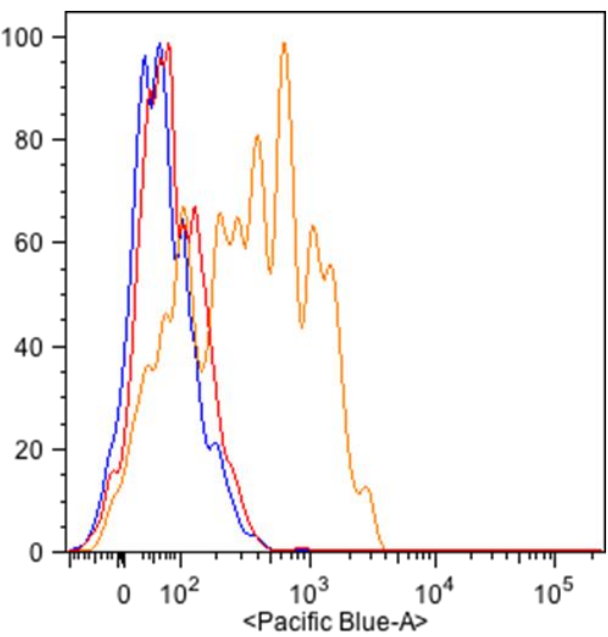

$\square$ 日pecimen_001_Saline.fcs 1.29 79.1

$\square$ 日 Specimen_001_500.fcs 1.0161.4

$\square$ 日 Specimen_001_antiige.fcs 0.82328

gMFI

Linha vermelha: solução salina

Linha azul: carboplatina

Linha laranja: anti IgE + carboplatina

Figura 8. Exemplo de resultado negativo do BAT expresso por gMFI (média geométrica de intensidade de fluorescência).

Avaliação das expressões de CD63 e CD203c após incubação com solução salina (controle negativo), carboplatina, e anti-lgE + carboplatina (controle positivo) em paciente tolerante à carboplatina. 
Solução salina

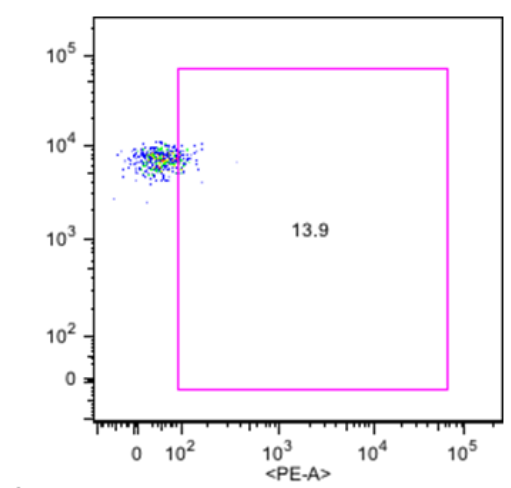

basos

Specimen_001_Saline.fcs

Event Count: 534

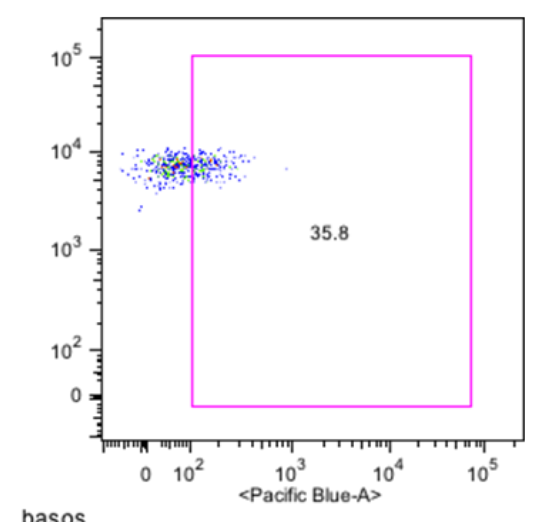

Specimen 001 Saline.fcs

Event Count: 534
Carboplatina

$500 \mathrm{mcg} / \mathrm{ml}$

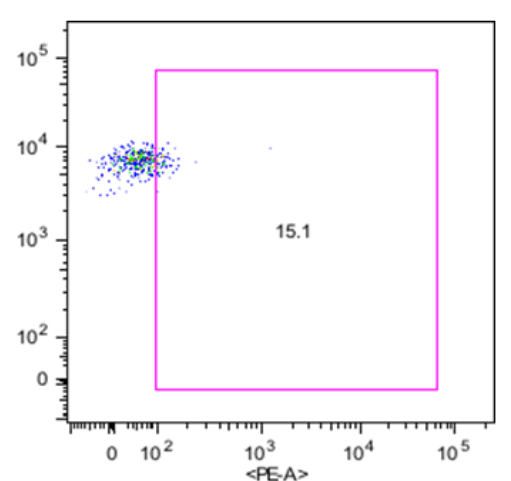

basos
Specimen_001_500.fcs
Event Count: 465

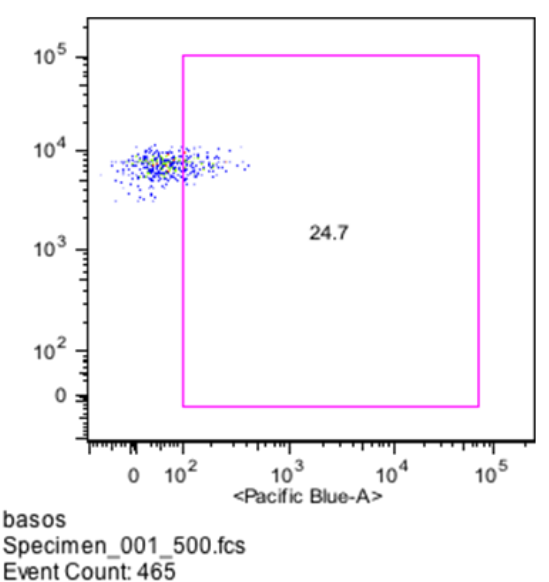

Anti-lgE

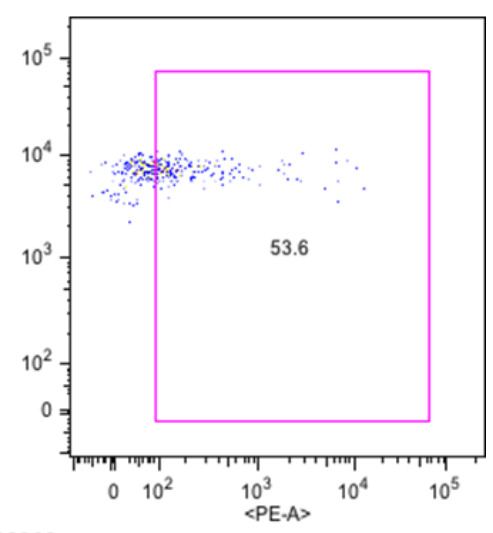

basos

Specimen_001_antige.fcs
Event Count: $36 \overline{4}$

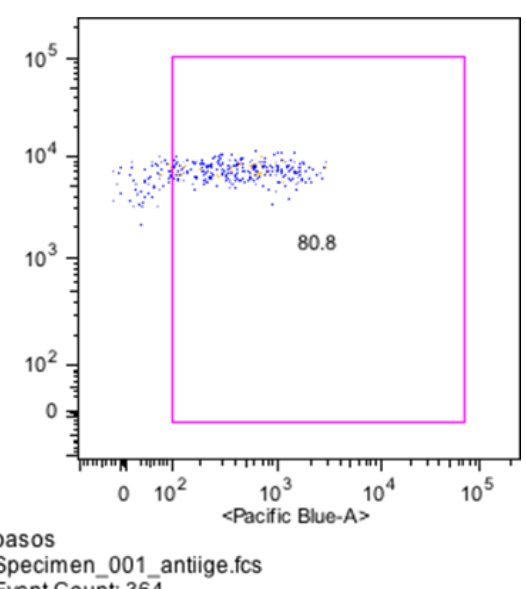

Specimen_001_antige.fcs

Figura 9. Exemplo de resultado negativo do BAT dado pelo percentual de células com expressão de CD63 e CD203c, após incubação com solução salina (controle negativo), carboplatina, e anti-lgE + carboplatina (controle positivo) em paciente tolerante à carboplatina 


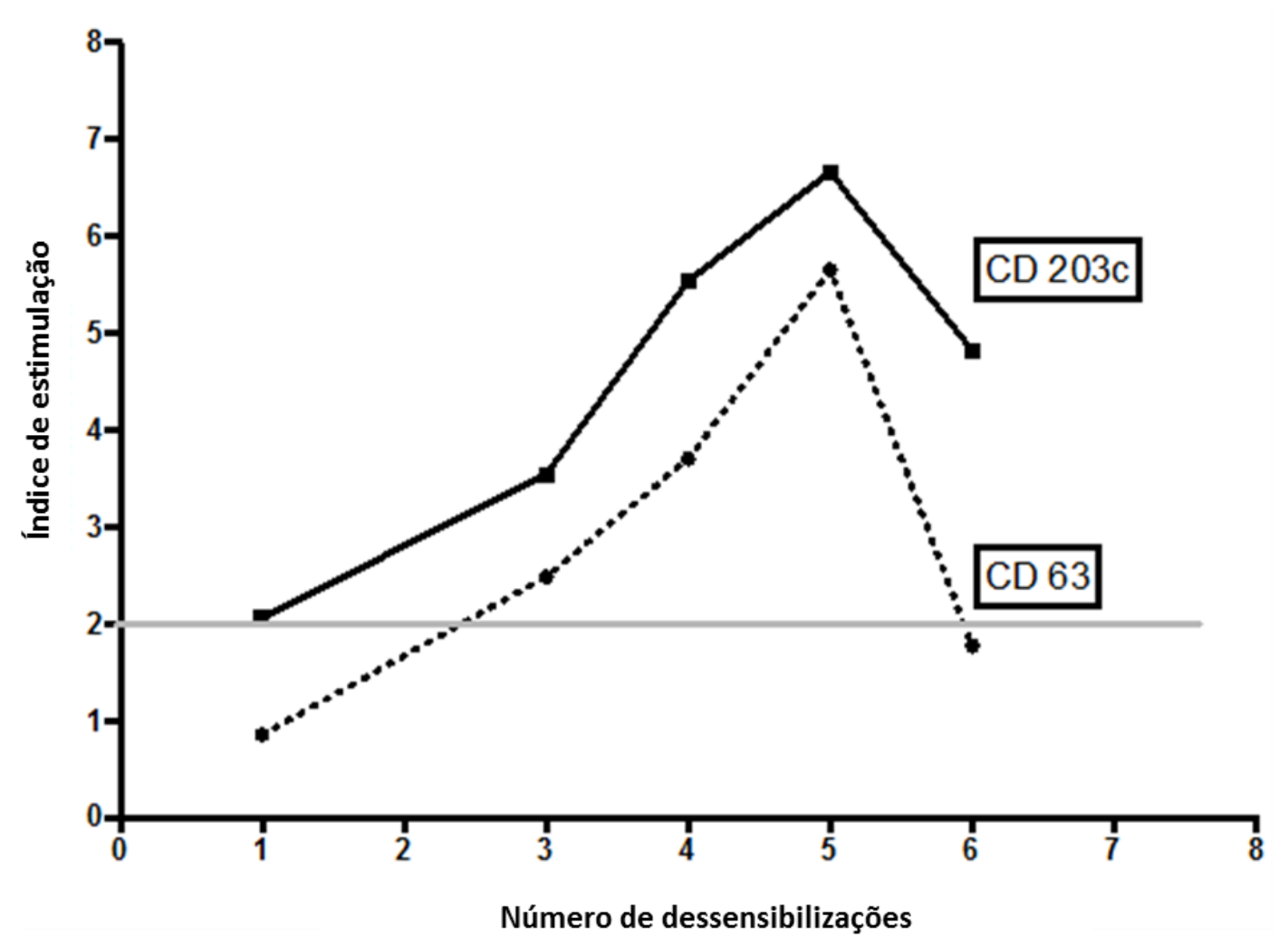

Figura 10. Evolução da expressão de CD203c e CD63 avaliada por meio do índice de estimulação em paciente alérgica à carboplatina submetida a múltiplas dessensibilizações 


\subsection{Estudo BRCA}

Dentre 239 registros de pacientes dessensibilizadas por reações de hipersensibilidade à carboplatina, 138 foram investigados para a presença da mutação do BRCA 1/2. A população avaliada $(n=138)$ era semelhante aos pacientes não avaliados para a mutação do BRCA 1/2 ( $n=101)$ nos quesitos idade, sexo, gravidade das reações iniciais, número de exposições prévias à carboplatina, incidência de reações durante dessensibilização e gravidade destas reações.

A média de idade foi de $60,6 \pm 10$ anos e não houve diferença

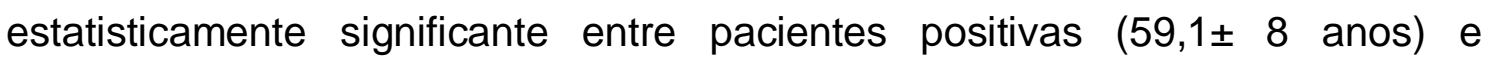
negativas (61,2 \pm 11 anos) para a mutação. A maioria das pacientes apresentava neoplasias malignas tubo-ovarianas $(91,3 \%, n=126)$, seguido de mamárias $(3,6 \%, n=5)$, peritoneais $(2,1 \%, n=3)$, peritoneal e ovariana $(2,1 \%$, $n=3)$, e endometrial $(0,7 \%, n=1)$.

A prevalência geral da mutação do BRCA foi de $34 \%(n=47)$, sendo $66 \%$ ( $n=31)$ portadoras da mutação do BRCA 1 e $34 \%(n=16)$ do BRCA 2. A média de exposições à carboplatina prévias à reação de hipersensibilidade foi de 9,9 $\pm 4,5$ para pacientes com a mutação versus $9,1 \pm 4,7$ sem a mutação ( $p=$ $0,37)$.

Pacientes positivas para a mutação BRCA apresentaram mais reações de hipersensibilidade imediata como reações iniciais do que aquelas sem a mutação (Figura 11a, $p=0,03$ ). Não houve diferença estatisticamente significante entre pacientes positivas e negativas para a mutação no quesito 
gravidade da reação inicial (Figura 11b, $p=0,22$ ). Testes cutâneos de leitura imediata foram positivos em $94 \%(n=44)$ das portadoras da mutação, versus $89 \%(n=81)$ nas negativas para a mutação $(p=0,33)$, sem distinção entre os grupos com relação à positividade durante prick ou intradérmico $(p=0,33)$.

Reações de hipersensibilidade imediata durante a dessensibilização à carboplatina ocorreram em $51 \%$ das pacientes portadoras da mutação versus em $27 \%$ das pacientes sem mutação (Figura 12a, $p<0,01$ ). A gravidade das reações ocorridas durante a dessensibilização apresentou distribuição semelhante entre os grupos (Figura 12b, $p=0,72$ ).

Níveis de triptase sérica foram obtidos durante reação inicial ou reação na dessensibilização em 14 pacientes negativas para a mutação e em 15 pacientes positivas. Em ambos os grupos, a média dos níveis de triptase durante a reação de hipersensibilidade inicial encontrava-se elevada (mutação do BRCA positiva: $13,4 \pm 13,1 \mu \mathrm{g} / \mathrm{L}$; mutação negativa: $13,6 \pm 13,4 \mu \mathrm{g} / \mathrm{L}$; valor de referência $\leq 11,5 \mu \mathrm{g} / \mathrm{L})$. Níveis de triptase obtidos durante reações ocorridas na dessensibilização foram mais elevados em pacientes portadoras da mutação (16,2 \pm 12,9 $\mu \mathrm{g} / \mathrm{L}$ versus $13,3 \pm 12 \mu \mathrm{g} / \mathrm{L})$, porém a diferença não foi estatisticamente significante (Figura 12c, $p=0,62$ ). 
A

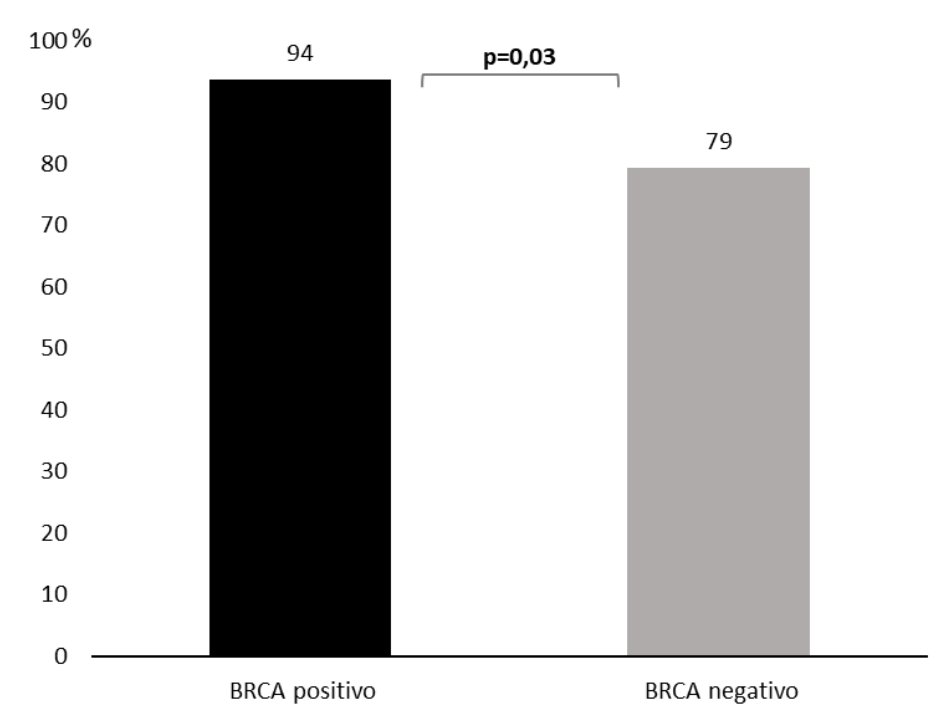

B

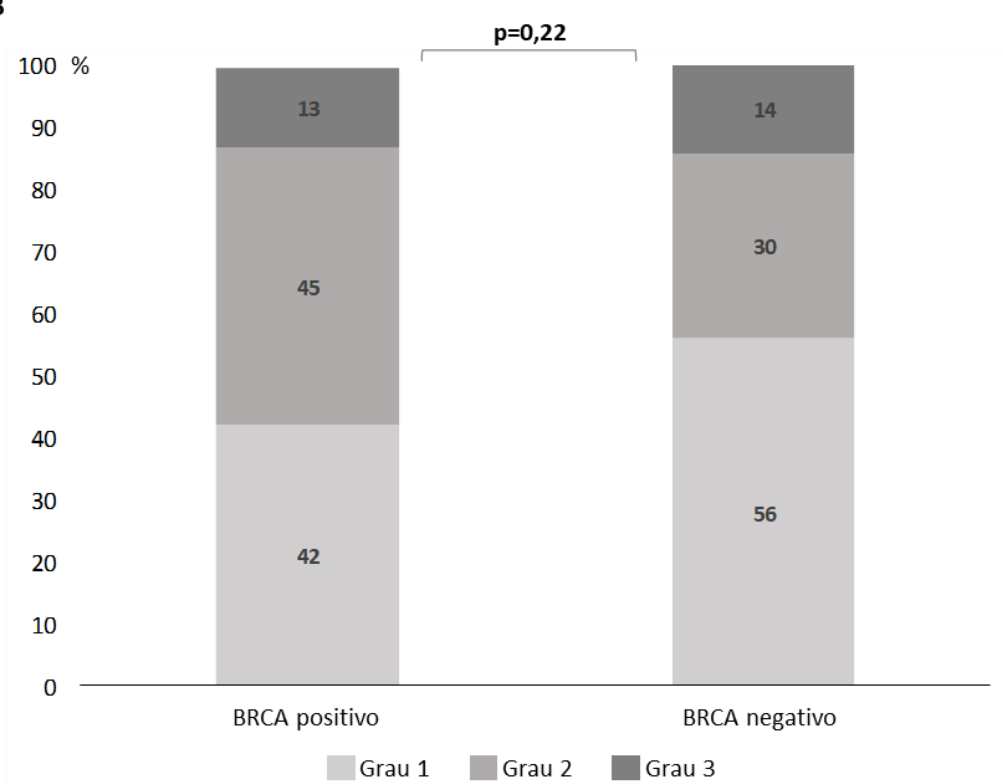

Figura 11. (a) Incidência de reações de hipersensibilidade imediata entre pacientes portadoras (BRCA positivo) e não portadoras (BRCA negativo) da mutação do BRCA 1/2. (b) Distribuição da gravidade das reações de hipersensibilidade iniciais à carboplatina entre portadoras (BRCA positivo) e não portadoras (BRCA negativo) da mutação do BRCA 1/2. 


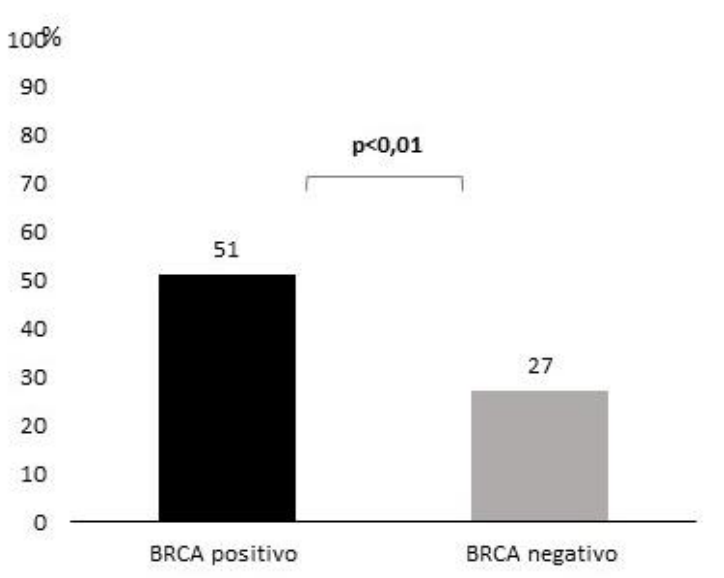

B

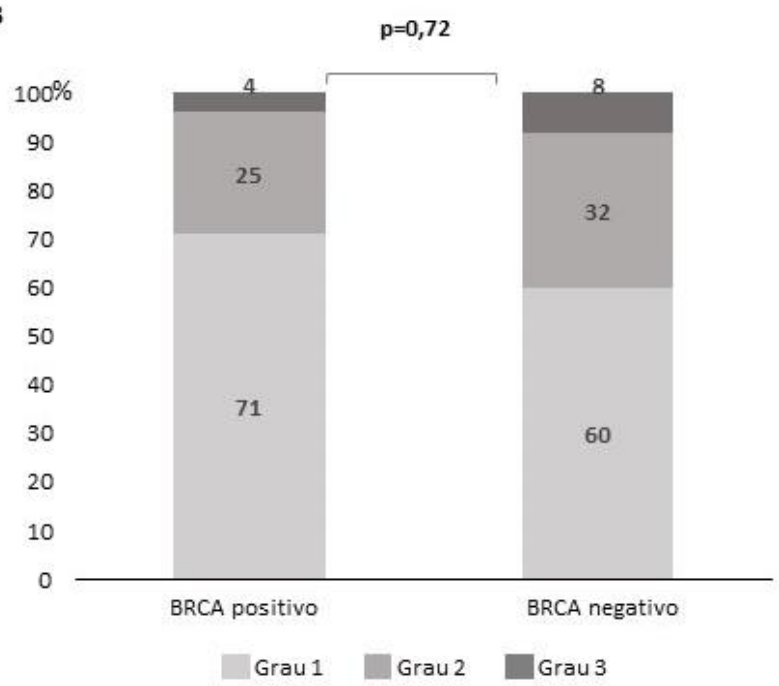

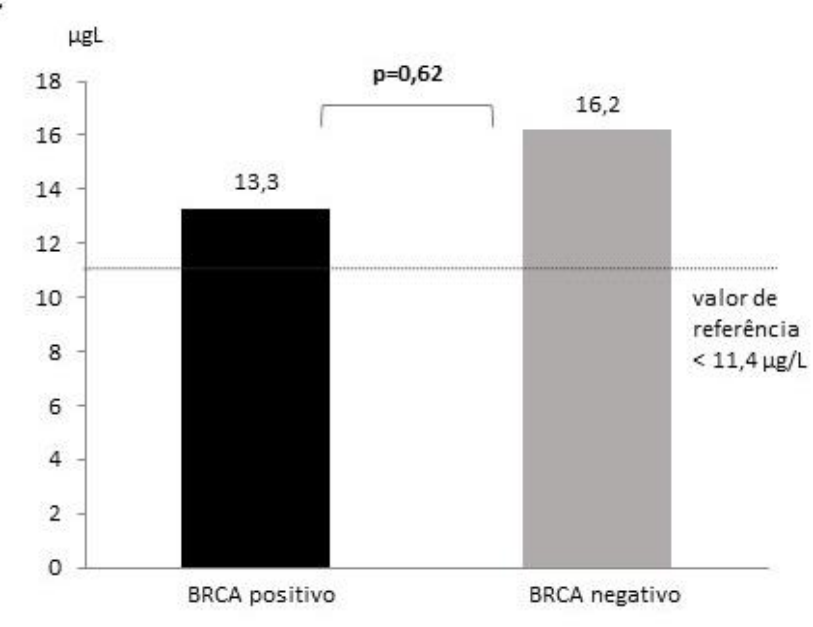

Figura 12. (a) Incidência de reações de hipersensibilidade imediata durante dessensibilização à carboplatina entre portadoras (BRCA positivo) e não portadoras (BRCA negativo) da mutação do BRCA 1/2. (b) Graus das reações ocorridas durante a dessensibilização entre portadoras (BRCA positivo) e não portadoras (BRCA negativo) da mutação do BRCA 1/2. (c) Média dos níveis de triptase durante reações de hipersensibilidade imediata ocorridas durante dessensibilização à carboplatina, em pacientes portadoras (BRCA positivo) e não portadoras (BRCA negativo) da mutação do BRCA $1 / 2$ (valor de referência $\leq 11,5 \mu \mathrm{g} / \mathrm{L}$ ). 
6. DISCUSSÃO 
Em nosso estudo pudemos avaliar a aplicação e relevância de biomarcadores na avaliação de reações de hipersensibilidade imediata às platinas, em especial, à carboplatina. Analisamos o perfil do BAT de pacientes alérgicas a platinas submetidas regularmente ao processo de dessensibilização. Também obtivemos informações referentes às reações ocorridas durante os procedimentos, incluindo os valores de triptase observados em algumas reações e pudemos correlacionar estas informações com os resultados do BAT. Os resultados sugerem que o BAT apresenta sensibilidade moderada e alta especificidade para o diagnóstico de alergia às platinas, além de auxiliar a predizer os pacientes com maior risco de reações durante a dessensibilização.

A indicação do procedimento de dessensibilização no grupo de pacientes estudadas foi baseada na ocorrência de reação de hipersensibilidade imediata associada à infusão de quimioterápico do grupo das platinas. A alta positividade do BAT observada deve se relacionar à persistência de reatividade dos basófilos e consequente probabilidade de reações clínicas durante os procedimentos de dessensibilização. Ambos os grupos controle formados por voluntários sadios que nunca haviam se exposto às platinas e pacientes tolerantes às mesmas apresentaram testes negativos, tanto na expressão de CD63 quanto de CD203c. Esses resultados demonstram que as platinas, nas concentrações utilizadas no BAT, não desencadeiam ativação inespecífica de basófilos, e não causam morte destas células, visto que a anti-lgE induziu expressão de CD63 e CD203c mesmo na presença do quimioterápico. 
O estudo apresenta um viés de seleção de pacientes, tendo em vista que a maioria dos pacientes referenciados ao Programa de Dessensibilização do BWH com indicação de uso de platinas é portadora de neoplasias ginecológicas, principalmente ovário e mama. Desta forma, pacientes que comumente recebem platinas para tratamento de outras neoplasias malignas, tais como portadores de câncer de pulmão e de cabeça e pescoço não se encontram representados nesta amostra. Existe associação conhecida entre o sexo feminino e risco de reações a alguns medicamentos [111] e estudos demonstraram que ser mulher é fator de risco independente para reações de hipersensibilidade à oxaliplatina em cânceres não ginecológicos [112, 113]. Não há informações suficientes para determinar se o câncer de ovário é associado a risco aumentado de alergia a platinas, tendo em vista que outros tipos de neoplasias malignas usualmente tratadas com platinas diferem em termos de expectativa de vida e número de exposições. Atopia encontrava-se presente em mais da metade das pacientes alérgicas de nossa amostra, indicando talvez que o perfil de resposta imune tipo 2 (T2) possa ser um fator de risco para alergia às platinas, como observado em outros estudos [8].

A mutação dos genes BRCA 1/2 aumenta a predisposição individual de desenvolvimento de câncer de mama e ovário, especialmente se associada à história familiar positiva para estas neoplasias. Estudo de Moon et al. indicou que a mutação do BRCA é fator de risco independente para a ocorrência de reações de hipersensibilidade à carboplatina, além de observar que os pacientes com a mutação também apresentavam a reação mais precocemente [106]. Não há relatos na literatura de associação entre os genes do BRCA, localizados no cromossomo 17, e genes ligados à atopia e anafilaxia, como IL- 
4, IL-5 e IL-13, localizados no cromossomo 5, ou IL-33, localizado no cromossomo 9.

No estudo BAT, observamos uma frequência maior da mutação BRCA1/2 em pacientes alérgicos $(44,4 \%)$, já que nenhum paciente do grupo controle exposto de maneira semelhante ao quimioterápico apresentou a mutação. Essa diferença apresentou significância estatística $(p=0,05)$, reforçando a associação entre o BRCA e reações de hipersensibilidade à carboplatina [106]. A observação da tendência de ocorrência elevada da mutação no grupo alérgico motivou a investigação da prevalência e do impacto da mutação do BRCA 1/2 na população ginecológica submetida à dessensibilização à carboplatina no BWH, com achados discutidos mais adiante.

A média do número de exposições à carboplatina antes da ocorrência da reação inicial observada no grupo de pacientes alérgicas foi de 9,9 ciclos. Este número é compatível com a literatura, em que há descrição de que reações à carboplatina ocorrem em média após a oitava exposição ao quimioterápico [11, 14, 34, 35]. Reações alérgicas à oxaliplatina tendem a ocorrer após o sexto ciclo [11, 14, 34], sendo que a média foi de 9 exposições nas pacientes avaliadas em nosso estudo. A alta média de exposições à carboplatina observada no grupo controle $1(18,2)$ nos permite inferir que estes pacientes possivelmente sejam de fato tolerantes ao medicamento e não desenvolverão reações alérgicas futuramente, tendo em vista o elevado número de exposições ao quimioterápico já ocorridas sem intercorrências clínicas.

O fato de $60 \%$ das pacientes alérgicas terem apresentado reações iniciais classificadas como grau 3 demonstra a gravidade e potencial letalidade das 
mesmas. Um procedimento que permite que o doente receba a medicação de primeira linha para o tratamento do câncer, mesmo tendo apresentado reação de hipersensibilidade grave prévia, mostra-se inovador e de grande importância. Nesse contexto, o marcador de ativação basofílica CD63 foi mais prevalente nas pacientes com reações iniciais mais graves (grau 3) do que naquelas com reações leves e moderadas (graus 1 e 2), o que aponta para seu potencial papel como preditor de reações graves de hipersensibilidade imediata às platinas.

Os valores de triptase obtidos após a reação que motivou a indicação da dessensibilização puderam ser resgatados dos prontuários de apenas três pacientes. Isto pode ser explicado pelo fato de que muitos médicos ainda não têm por hábito a solicitação rotineira deste exame na avaliação de reações de hipersensibilidade imediata. A distinção entre reações de hipersensibilidade imediata associadas à ativação de mastócitos/basófilos e outras reações que não envolvem estas células é de suma importância para a investigação adicional posterior e manejo do paciente. A triptase coletada após a reação pode auxiliar nesta diferenciação, uma vez que a apresentação clínica pode ser semelhante nos dois casos. Em nossa casuística, uma paciente apresentou reação subjetiva caracterizada por sensação de ansiedade, mal-estar e aumento dos níveis pressóricos durante a dessensibilização e a triptase não foi solicitada. O BAT que havia sido realizado no mesmo dia, previamente ao início da quimioterapia, mostrou-se negativo, sugerindo que a reação não desencadeou ativação basofílica. Possivelmente neste caso a triptase apresentaria valores dentro do limite da normalidade, o que indicaria ausência de ativação de mastócitos e auxiliaria no diagnóstico do tipo de reação. 
Exemplo de reação de hipersensibilidade em que predomina ativação basofílica em detrimento de ativação mastocitária pode ser visto na paciente 15. Essa paciente apresenta prick positivo na menor concentração de oxaliplatina e evoluiu com reação grau 1 durante sua primeira dessensibilização. Os níveis de triptase coletados após a reação foram baixos $(5,2 \mu \mathrm{g} / \mathrm{L}$; valor de referência $\leq 11,5 \mu \mathrm{g} / \mathrm{L})$, mas ambos os marcadores de ativação basofílica foram positivos. Pode-se especular nesse caso que tenha havido liberação mínima de triptase proveniente de basófilos, o que ocasionou discreta elevação de seus níveis, tendo em vista que o nível basal da paciente obtido em outra ocasião foi de $3,7 \mu \mathrm{g} / \mathrm{L}$. O mesmo não ocorreu com as pacientes 5 e 8; essas últimas, apesar de também terem apresentado reações grau 1, evoluíram com aumento maciço de triptase sérica $(56,2 \mu \mathrm{g} / \mathrm{L}$ e 42,8 $\mu \mathrm{g} / \mathrm{L}$, respectivamente) e BAT positivo para os dois marcadores, sugerindo fortemente participação ativa dos mastócitos no processo. O BAT poderia ter papel auxiliar na identificação de reações de hipersensibilidade imediata mediadas preponderantemente por basófilos, na medida em que nesses casos não se espera grandes elevações da triptase sérica e os marcadores CD63 e CD203c devem apresentar aumento de expressão.

As 15 pacientes alérgicas estudadas apresentaram testes cutâneos de leitura imediata positivos. Este teste é realizado geralmente na primeira avaliação ambulatorial pelo alergista e quando positivo ajuda a embasar a indicação do procedimento de dessensibilização [90], por sinalizar a presença de anticorpo IgE-específico contra a droga. Testes cutâneos são ferramentas diagnósticas utilizadas para identificar pacientes alérgicos às platinas, no entanto, apresentam algumas limitações que incluem a variação de 
sensibilidade dependente do tempo decorrido da exposição ao alérgeno; o desencadeamento de reações irritativas locais com concentrações altas de alérgeno; a necessidade de se aguardar duas semanas após a reação, devido ao período refratário; e o risco de reações sistêmicas. Desta forma, um teste in vitro como o BAT poderia auxiliar na identificação de pacientes alérgicos, de maneira menos invasiva.

Caiado et al estudaram a $\lg E$ sérica específica às platinas como método adicional de investigação e, embora a especificidade para a $\lg E$ sérica à carboplatina seja elevada (100\%), a sensibilidade encontrada foi de $58 \%$. Para a oxaliplatina, a sensibilidade foi maior (75\%), porém com menor especificidade (75\%) [42]. Em nosso estudo, o BAT padronizado para carboplatina e oxaliplatina apresentou moderada sensibilidade $(73,3 \%)$ e correlacionou-se aos testes cutâneos positivos encontrados no grupo de pacientes alérgicas. Ambos grupos controle apresentaram BAT negativos, apontando para a elevada especificidade do teste (100\%).

O objetivo original do trabalho era a realização do BAT antes da dessensibilização e a repetição do mesmo ao término do procedimento. Alguns testes foram realizados neste segundo momento, por meio da coleta de amostra de sangue após a dessensibilização, porém todos apresentaram-se negativos. Esta observação foi atribuída ao uso profilático de corticosteroides pelos pacientes antes do início da dessensibilização e consequente negativação do BAT. Portanto, optou-se pela exclusão desta análise.

O tempo prolongado transcorrido entre exposições às platinas propicia muitas vezes a ocorrência de reações graves [41]. Em nossa casuística, o 
tempo médio entre a última exposição ao quimioterápico e a dessensibilização foi de 30,2 dias, encontrando-se na média do intervalo habitual entre aplicações de quimioterápicos do grupo das platinas [8]. Uma doente do grupo estudado (paciente 5) apresentou tempo de seis meses entre a última aplicação de carboplatina e sua primeira dessensibilização. Esta paciente apresentou as reações mais graves dentro do grupo estudado, além de ter reações clínicas em quatro das cinco dessensibilizações às quais foi submetida. Isto pode sinalizar a necessidade de diminuição do tempo para a indicação inicial do procedimento de dessensibilização, tendo em vista que seriam reduzidas as chances de reações graves na reexposição.

A maioria das reações ocorridas durante os procedimentos foram classificadas como grau 1 ( $n=10 ; 76,9 \%)$, o que demonstra que a dessensibilização é segura e bem tolerada. Castells et al, em avaliação de 413 procedimentos de dessensibilização para agentes quimioterápicos, registraram reações leves em $27 \%$ dos casos e ausência de reações em $67 \%$ dos procedimentos $[8,99]$. Apenas $6 \%$ dos procedimentos desencadearam reações classificadas como graves, ainda assim de menor gravidade do que a reação inicial [8, 99]. Em avaliação mais recente do mesmo grupo, envolvendo 2177 dessensibilizações para quimioterápicos e anticorpos monoclonais, os dados encontrados foram semelhantes: incidência de reações leves em 19\%, ausência de reações em $74 \%$ e reações moderadas ou graves em $7 \%$ dos procedimentos [99]. Em nosso grupo de pacientes alérgicas, apenas três apresentaram reações grau 2 ou 3 durante a dessensibilização, em todos os casos com a resolução do quadro após a interrupção da infusão e instituição de tratamento adequado. 
O BAT persistia positivo em diferentes cursos de dessensibilização para algumas pacientes (pacientes 1, 3, 5, 13 e 15). Essa observação nos leva a inferir que o estado de hiporresponsividade de basófilos induzido pela dessensibilização seja transitório e que justifique, portanto, a necessidade da repetição do procedimento em todas as infusões subsequentes da droga.

$O$ alto percentual de positividade do BAT nas doentes que reagiram durante a dessensibilização, mesmo encontrando-se medicadas com drogas profiláticas, mostra que a positividade do teste apresenta correlação com a ocorrência de reações clínicas. O aumento na expressão de CD203c em número elevado de reações (12/13), quando comparado ao CD63 (9/13) pode indicar que o primeiro seja um marcador mais sensível para a ocorrência de reações durante a dessensibilização. A sensibilidade aumentada do CD203c em comparação ao CD63 já foi relatada em estudo com pacientes alérgicos a amendoim [67] e em estudo com pacientes alérgicos ao látex [66]. No entanto, foi observada alta positividade (50\%) na expressão de CD203c nos 14 procedimentos sem ocorrência de reações. Este dado pode ser interpretado de duas formas: o CD203c seria um marcador com baixa especificidade para a ocorrência de reações clínicas [67]; ou que tais pacientes com expressão elevada poderiam evoluir clinicamente com reações de hipersensibilidade caso não tivessem sido pré-medicadas e dessensibilizadas, tendo em vista que apresentam basófilos potencialmente reativos. Foi proposto que a expressão de CD203c também possa ser induzida por receptor específico na superfície da célula e não dependente de ativação mediada por FcદRI [114]. Estudo de 2007 demonstrou que o estímulo com IL-3 levou a aumento de expressão de CD203c na superfície do basófilo não acompanhada de aumento de CD63, por 
via dependente de PI3-quinase, tanto em pacientes alérgicos a pólen quanto em participantes saudáveis [114].

A paciente 5 apresentou aumento sequencial na expressão de ambos os marcadores de ativação de basófilos, o que se correlacionou com a ocorrência de reações clínicas nas quatro dessensibilizações iniciais. De maneira oposta, na última dessensibilização notamos na Figura 10 redução marcante na expressão dos dois marcadores pela primeira vez, coincidindo com a ausência de reação clínica neste procedimento.

Em nosso estudo foi demonstrado que o BAT de pacientes alérgicos à carboplatina e à oxaliplatina tende a ser positivo quando realizado antes de dessensibilizações que apresentaram reações de hipersensibilidade. Neste cenário, o uso do CD63 e CD203c como biomarcadores com potencial de predizer a ocorrência de reações clínicas pode aumentar o perfil de segurança das dessensibilizações. Atualmente, a estratificação de risco de pacientes alérgicos candidatos ao procedimento baseia-se na avaliação ambulatorial inicial realizada pelo alergista e no resultado de testes cutâneos, porém estes não predizem os pacientes com maior risco de nova reação.

Estudo prospectivo de 2012 seguiu pacientes oncológicos que recebiam carboplatina e avaliou a expressão de CD203c em seis doentes que se tornaram alérgicos durante o acompanhamento [88]. Os autores inferiram que o CD203c seria um marcador para a ocorrência de reações anafiláticas secundárias à carboplatina e que estas seriam de maior gravidade (anafilaxias graus 2 a 4), tendo em vista que no dia precedente à ocorrência da reação alérgica os basófilos de cinco doentes apresentavam aumento na expressão de 
CD203c e estes pacientes evoluíram com anafilaxias graves. O desenho e metodologia deste estudo diferem do nosso na medida em que o BAT utilizado provinha de kit comercial (Allergenicity Kit, Beckman Coulter), o CD63 não foi utilizado como marcador de ativação de basófilos, nenhum paciente selecionado foi submetido à realização de teste cutâneo de leitura imediata com carboplatina, e os doentes não foram dessensibilizados. Entretanto, os achados do referido estudo [88] reforçam a possibilidade de uso do CD203c como um biomarcador para a ocorrência de reações alérgicas à carboplatina.

A triptase é a principal protease liberada durante a ativação mastocitária e também se encontra presente em pequena quantidade nos basófilos [115]. Três pacientes foram avaliados durante a reação de hipersensibilidade inicial e dois apresentaram níveis elevados (média de 20,1 $\mu \mathrm{g} / \mathrm{L}$ ), sinalizando ativação mastocitária durante reação de hipersensibilidade à platina. Além disso, a triptase estava elevada (> 11,5 $\mu \mathrm{g} / \mathrm{L}$ ) nas 5 reações ocorridas durante dessensibilizações em que ambos CD63 e CD203c também apresentavam aumento de expressão, indicando que a ativação mastocitária nestas reações foi associada a uma expressão paralela de marcadores de ativação em basófilos humanos. É importante salientar que o BAT não se correlacionou com a triptase sérica no caso da paciente 10 , em que mesmo não apresentando reação clínica, os níveis de triptase encontravam-se elevados e ambos os marcadores de ativação dos basófilos foram negativos. A reação clínica pode ter sido mascarada pelo uso profilático de corticoides e anti-histamínicos, mas seria esperada elevação dos marcadores de basófilos. Os resultados do nosso estudo referentes ao BAT e sua correlação com os níveis de triptase sérica foram publicados recentemente [116]. 
A mutação do BRCA 1/2 apresentou prevalência aumentada na casuística avaliada de pacientes com neoplasias malignas ginecológicas submetidas à dessensibilização à carboplatina (34\%; $n=47 / 138)$. A prevalência da mutação em pacientes com neoplasias malignas tubo-ovarianas varia de 13 a 17\%, e é em torno de $6,1 \%$ em pacientes portadoras de câncer de mama tratadas no DFCl [117]. A alta prevalência da mutação encontrada no nosso estudo corrobora a ideia de que a mesma seja um fator de risco independente para reações de hipersensibilidade à carboplatina [106]. Podemos sugerir preliminarmente que pacientes portadores da mutação para o BRCA poderiam ser submetidos à realização do BAT após 8 ciclos de platinas para se avaliar a presença de reatividade basofílica e, desta forma, aumentar a segurança durante infusões subsequentes.

Pacientes positivas para a mutação apresentaram mais reações imediatas, possivelmente lgE-mediadas, como apresentação clínica inicial do que pacientes sem a mutação. Reações à carboplatina tendem a apresentar padrão sugestivo de reação lgE-mediada, no entanto são descritos casos de reações mistas, com características de lgE-mediada e de tempestade de citocinas, e são encontrados ainda casos com apresentação clínica tardia, com predomínio de manifestações cutâneas. Nosso achado sugere que a administração de carboplatina para pacientes portadoras da mutação deva ser feita sob supervisão intensificada, já que essas pacientes tendem a apresentar manifestação imediata típica de reação lgE-mediada, podendo evoluir para anafilaxia grave e requerer pronta intervenção médica. 
Com relação à gravidade das reações iniciais, observou-se que a distribuição entre leve, moderada e grave foi semelhante nos dois grupos do estudo BRCA (pacientes positivas e negativas para a mutação) $(p=0,22)$, mesmo verificando-se que reações grau 1 foram discretamente mais prevalentes nas pacientes negativas para a mutação e reações grau 2 em pacientes positivas para a mutação. Isto pode ser devido ao fato de que muitas pacientes já recebem como profilaxia corticoides e anti-histamínicos, medicações essas que podem mascarar a gravidade das reações iniciais. Embora Moon et al tenham relatado que pacientes positivas para a mutação do BRCA tendam a desenvolver reações com dose cumulativa menor, em nossa população o número médio de exposições prévias à carboplatina foi semelhante em ambos os grupos [106].

As pacientes portadoras da mutação do BRCA 1/2 foram mais suscetíveis à ocorrência de reações de hipersensibilidade imediata durante a dessensibilização $(p<0,01)$, o que novamente aponta para a necessidade de se aumentar a vigilância durante a infusão desse grupo de pacientes. Com relação à gravidade dessas reações, as pacientes positivas apresentaram o mesmo padrão das negativas, realçando a segurança da dessensibilização.

Os níveis de triptase sérica encontravam-se elevados em reações ocorridas durante a dessensibilização nos dois grupos. Esse achado confirma o papel da triptase sérica como método diagnóstico auxiliar na avaliação de reações imediatas induzidas por medicamentos, quando obtida nos primeiros 30 a 120 minutos da reação. 
Testes cutâneos foram positivos em $94 \%$ das pacientes positivas para a mutação versus $89 \%$ nas negativas. Embora não seja significativo, esse achado pode sugerir que algumas das reações no grupo de pacientes negativas sejam não IgE-mediadas, e possam apresentar inclusive mecanismo misto ou mesmo relacionado à tempestade de citocinas, o que é compatível com o achado de que pacientes positivas para a mutação tenham apresentado mais reações de hipersensibilidade imediata do que as pacientes negativas.

Podemos sugerir de maneira preliminar que a presença da mutação BRCA $1 / 2$ e sua associação com reações de hipersensibilidade imediata à carboplatina possam explicar parcialmente o fato de que a maioria dos doentes referenciados ao programa de dessensibilização do BWH seja formada por pacientes portadoras de neoplasias ginecológicas [8, 118]. São necessários mais estudos para que se estabeleça se as mutações nos genes BRCA 1 e 2 podem influenciar a expressão de genes Th2 e aumentar níveis de IgE sérica específica para a carboplatina, e/ou amplificar transduções de sinais durante a ativação mastocitária em resposta à carboplatina [118]. Os resultados da análise da prevalência da mutação do BRCA 1/2 e seu impacto nas pacientes submetidas à dessensibilização à carboplatina foram publicados recentemente [119]. 
7. CONCLUSÕES 
Por meio dos achados do nosso estudo pudemos observar que:

- $\quad$ A realização do BAT e a pesquisa da mutação dos genes BRCA 1 e 2 forneceram informações relevantes a respeito de candidatos à dessensibilização às platinas e constituíram-se em bons biomarcadores para a avaliação de reações de hipersensibilidade nessa população.

- O BAT apresentou moderada sensibilidade $(73,3 \%)$ e alta especificidade (100\%) nas pacientes alérgicas às platinas submetidas regularmente ao procedimento de dessensibilização e pode se tornar uma ferramenta auxiliar no diagnóstico desses indivíduos.

- $\quad$ BAT persistiu positivo em diferentes cursos de dessensibilização. Esse dado sugere que o procedimento induza hiporresponsividade transitória dos basófilos e enfatiza a necessidade de manutenção da dessensibilização em pacientes alérgicos às platinas.

- A maioria das pacientes que reagiram durante o procedimento de dessensibilização apresentavam BAT positivo, o que aponta para o papel preditivo do teste.

- A expressão da proteína CD203c apresentou maior sensibilidade no diagnóstico de pacientes alérgicos às platinas, enquanto que a CD63 foi mais específica em predizer pacientes que reagiram durante a dessensibilização, e pacientes que apresentaram reações iniciais mais graves.

- A triptase sérica correlacionou-se com o BAT na amostra estudada. Isto corrobora o uso conjunto dos dois métodos de avaliação em casos de reações alérgicas às platinas ocorridas durante a dessensibilização.

- A prevalência da mutação dos genes BRCA1/2 encontrada nas pacientes alérgicas à carboplatina submetidas à dessensibilização foi elevada e 
as portadoras da mutação tenderam a reagir mais durante o procedimento de dessensibilização.

- O conhecimento de possíveis biomarcadores preditores de reações durante a dessensibilização aos quimioterápicos do grupo das platinas pode aumentar a segurança do procedimento e auxiliar na manutenção do esquema quimioterápico de primeira linha do paciente. 
8. ANEXO 
Dentre as pacientes que apresentavam BAT positivo, observou-se um elevado percentual de pacientes reatoras durante a dessensibilização, para ambos marcadores de ativação: CD63 (9/10; 90\%), Tabela A1; e CD203c (12/19;63,2\%), Tabela A2.

Tabela A1. Resultados do teste de ativação de basófilos por marcador de ativação de basófilo (CD63) entre pacientes com e sem reação clínica durante a dessensibilização.

\begin{tabular}{|c|c|c|c|}
\hline & BAT positivo & BAT negativo & Total \\
\hline $\begin{array}{c}\text { Reação durante } \\
\text { DS }\end{array}$ & 9 & 4 & 13 \\
\hline $\begin{array}{c}\text { Sem reação } \\
\text { durante DS }\end{array}$ & 1 & 13 & 14 \\
\hline Total & 10 & 17 & 27 \\
\hline
\end{tabular}

DS: dessensibilização

Tabela A2. Resultados do teste de ativação de basófilos por marcador de ativação de basófilo (CD203c) entre pacientes com e sem reação clínica durante a dessensibilização.

\begin{tabular}{|c|c|c|c|}
\hline & BAT positivo & BAT negativo & Total \\
\hline $\begin{array}{c}\text { Reação durante } \\
\text { DS }\end{array}$ & 12 & 1 & 13 \\
\hline $\begin{array}{c}\text { Sem reação } \\
\text { durante DS }\end{array}$ & 7 & 7 & 14 \\
\hline Total & 19 & 8 & 27 \\
\hline
\end{tabular}

DS: dessensibilização 
9. REFERÊNCIAS 
1. Jemal A, Siegel R, Ward E, Hao Y, Xu J, Murray T, Thun MJ. Cancer statistics, 2008. CA. Cancer J. Clin. 2008; 58: 71-96.

2. Jemal A, Siegel R, Xu J, Ward E. Cancer Statistics, 2010. CA. Cancer J. Clin. 2010; 60: 277-300.

3. Centers for Disease Control and Prevention. Deaths, percent of total deaths, and death rates for the 15 leading causes of death in 10-year age groups, by race and sex: United States 1999-2014 [Internet]. 2017.Disponível em: https://www.cdc.gov/nchs/nvss/mortality/lcwk2.htm.

4. World Health Organization, International Agency for Research on Cancer. GLOBOCAN 2012 - Estimated cancer incidence, mortality and prevalence worldwide in 2012 [Internet]. 2013. Disponível em: http://globocan.iarc.fr.

5. Instituto Nacional de Câncer José Alencar Gomes da Silva. Coordenação de Prevenção e Vigilância. Estimativa 2016: Incidência de Câncer no Brasil [Internet]. 2015. Disponível em: http://www.inca.gov.br/estimativa/2016/

6. Siegel R, Naishadham D, Jemal A. Cancer statistics, 2013. CA. Cancer J. Clin. 2013; 63: 11-30.

7. Shepherd GM. Hypersensitivity reactions to chemotherapeutic drugs. Clin. Rev. Allergy Immunol. 2003; 24: 253-262.

8. Castells MC, Tennant NM, Sloane DE, Hsu FI, Barrett NA, Hong DI, Laidlaw TM, Legere HJ, Nallamshetty SN, Palis RI, Rao JJ, Berlin ST, Campos SM, Matulonis UA. Hypersensitivity reactions to chemotherapy: outcomes and safety of rapid desensitization in 413 cases. J. Allergy Clin. Immunol. 2008; 122: 574-580. 
9. Lenz H-J. Management and Preparedness for Infusion and Hypersensitivity Reactions. The Oncologist 2007; 12: 601-609.

10. Jerschow E, Lin RY, Scaperotti MM, McGinn AP. Fatal anaphylaxis in the United States 1999-2010: temporal patterns and demographic associations. J. Allergy Clin. Immunol. 2014; 134: 1318-1328.e7.

11. Castells M, Sancho-Serra M del C, Simarro M. Hypersensitivity to antineoplastic agents: mechanisms and treatment with rapid desensitization. Cancer Immunol. Immunother. CII 2012; 61: 1575-1584.

12. Goldberg A, Confino-Cohen R, Fishman A, Beyth $\mathrm{Y}$, Altaras M. A modified, prolonged desensitization protocol in carboplatin allergy. J. Allergy Clin. Immunol. 1996; 98: 841-843.

13. Giavina-Bianchi P, Patil SU, Banerji A. Immediate Hypersensitivity Reaction to Chemotherapeutic Agents. J. Allergy Clin. Immunol. Pract. 2017; 5: 593-599.

14. Markman M BJ, Kennedy A WK, Elson P PG, Kulp B. Clinical Features of Hypersensitivity Reactions to Carboplatin. J. Clin. Oncol. Off. J. Am. Soc. Clin. Oncol. 1999; 17: 1141-1145.

15. Johansson SGO, Bieber T, Dahl R, Friedmann PS, Lanier BQ, Lockey RF, Motala C, Ortega Martell JA, Platts-Mills TAE, Ring J, Thien F, Van Cauwenberge P, Williams HC. Revised nomenclature for allergy for global use: Report of the Nomenclature Review Committee of the World Allergy Organization, October 2003. J. Allergy Clin. Immunol. 2004; 113: 832836.

16. Bircher AJ, Scherer Hofmeier K. Drug hypersensitivity reactions: Inconsistency in the use of the classification of immediate and 
nonimmediate reactions. J. Allergy Clin. Immunol. 2012; 129: 263-264; author reply 265-266.

17. Demoly P, Adkinson NF, Brockow K, Castells M, Chiriac AM, Greenberger PA, Khan DA, Lang DM, Park H-S, Pichler W, Sanchez-Borges M, Shiohara T, Thong BY-H. International Consensus on drug allergy. Allergy 2014; 69: 420-437.

18. Simons FER. Anaphylaxis. J. Allergy Clin. Immunol. 2010; 125: S161-181.

19. Sampson HA, Muñoz-Furlong A, Campbell RL, Adkinson NF, Bock SA, Branum A, Brown SGA, Camargo CA, Cydulka R, Galli SJ, Gidudu J, Gruchalla RS, Harlor AD, Hepner DL, Lewis LM, Lieberman PL, Metcalfe DD, O'Connor R, Muraro A, Rudman A, Schmitt C, Scherrer D, Simons FER, Thomas S, Wood JP, Decker WW. Second symposium on the definition and management of anaphylaxis: Summary report-Second National Institute of Allergy and Infectious Disease/Food Allergy and Anaphylaxis Network symposium. J. Allergy Clin. Immunol. 2006; 117: 391-397.

20. Simons FER, Ardusso LRF, Bilò MB, El-Gamal YM, Ledford DK, Ring J, Sanchez-Borges M, Senna GE, Sheikh A, Thong BY, World Allergy Organization. World Allergy Organization anaphylaxis guidelines: summary. J. Allergy Clin. Immunol. 2011; 127: 587-593.e1-22.

21. Harper NJN, Dixon T, Dugué P, Edgar DM, Fay A, Gooi HC, Herriot R, Hopkins P, Hunter JM, Mirakian R, Pumphrey RSH, Seneviratne SL, Walls AF, Williams P, Wildsmith JA, Wood P, Nasser AS, Powell RK, Mirakhur R, Soar J, Working Party of the Association of Anaesthetists of 
Great Britain and Ireland. Suspected anaphylactic reactions associated with anaesthesia. Anaesthesia 2009; 64: 199-211.

22. Castells M. Diagnosis and management of anaphylaxis in precision medicine. J. Allergy Clin. Immunol. 2017; 140: 321-333.

23. Farnam K, Chang C, Teuber S, Gershwin ME. Nonallergic drug hypersensitivity reactions. Int. Arch. Allergy Immunol. 2012; 159: 327345.

24. Liew WK, Williamson E, Tang MLK. Anaphylaxis fatalities and admissions in Australia. J. Allergy Clin. Immunol. 2009; 123: 434-442.

25. Sole D, Ivancevich JC, Borges MS, Coelho MA, Rosario NA, Ardusso LRF, Bernd LAG, Latin American Anaphylaxis Working Group. Anaphylaxis in Latin America: a report of the online Latin American survey on anaphylaxis (OLASA). Clinics 2011; 66: 943-947.

26. Turner PJ, Jerschow E, Umasunthar T, Lin R, Campbell DE, Boyle RJ. Fatal Anaphylaxis: Mortality Rate and Risk Factors. J. Allergy Clin. Immunol. Pract. 5: 1169-1178.

27. Tanno LK, Ganem F, Demoly $\mathrm{P}$, Toscano CM, Bierrenbach AL. Undernotification of anaphylaxis deaths in Brazil due to difficult coding under the ICD-10. Allergy 2012; 67: 783-789.

28. Aun MV, Blanca M, Garro LS, Ribeiro MR, Kalil J, Motta AA, Castells M, Giavina-Bianchi P. Nonsteroidal anti-inflammatory drugs are major causes of drug-induced anaphylaxis. J. Allergy Clin. Immunol. Pract. 2014; 2: 414-420. 
29. Renaudin J-M, Beaudouin E, Ponvert C, Demoly P, Moneret-Vautrin D-A. Severe drug-induced anaphylaxis: analysis of 333 cases recorded by the Allergy Vigilance Network from 2002 to 2010. Allergy 2013; 68: 929-937.

30. Turner PJ, Gowland MH, Sharma V, lerodiakonou D, Harper N, Garcez T, Pumphrey R, Boyle RJ. Increase in anaphylaxis-related hospitalizations but no increase in fatalities: an analysis of United Kingdom national anaphylaxis data, 1992-2012. J. Allergy Clin. Immunol. 2015; 135: 956963.e1.

31. Mullins RJ, Wainstein BK, Barnes EH, Liew WK, Campbell DE. Increases in anaphylaxis fatalities in Australia from 1997 to 2013. Clin. Exp. Allergy 2016; 46: 1099-1110.

32. Stuart GCE, Kitchener H, Bacon M, duBois A, Friedlander M, Ledermann J, Marth C, Thigpen T, Trimble E, participants of 4th Ovarian Cancer Consensus Conference (OCCC), Gynecologic Cancer Intergroup. 2010 Gynecologic Cancer InterGroup (GCIG) consensus statement on clinical trials in ovarian cancer: report from the Fourth Ovarian Cancer Consensus Conference. Int. J. Gynecol. Cancer 2011; 21: 750-755.

33. Aabo K, Adams M, Adnitt P, Alberts DS, Athanazziou A, Barley V, Bell DR, Bianchi U, Bolis G, Brady MF, Brodovsky HS, Bruckner H, Buyse M, Canetta R, Chylak V, Cohen CJ, Colombo N, Conte PF, Crowther D, Edmonson JH, Gennatas C, Gilbey E, Gore M, Guthrie D, Yeap BY. Chemotherapy in advanced ovarian cancer: four systematic metaanalyses of individual patient data from 37 randomized trials. Advanced Ovarian Cancer Trialists' Group. Br. J. Cancer 1998; 78: 1479-1487. 
34. Makrilia N, Syrigou E, Kaklamanos I, Manolopoulos L, Saif MW. Hypersensitivity Reactions Associated with Platinum Antineoplastic Agents: A Systematic Review. Met.-Based Drugs 2010; 2010: 1-11.

35. Picard M, Matulonis UA, Castells M. Chemotherapy hypersensitivity reactions in ovarian cancer. J. Natl. Compr. Cancer Netw. 2014; 12: 389402.

36. André T, Boni C, Navarro M, Tabernero J, Hickish T, Topham C, Bonetti A, Clingan P, Bridgewater J, Rivera F, de Gramont A. Improved overall survival with oxaliplatin, fluorouracil, and leucovorin as adjuvant treatment in stage II or III colon cancer in the MOSAIC trial. J. Clin. Oncol. 2009; 27: 3109-3116.

37. Conroy T, Paillot B, François E, Bugat R, Jacob J-H, Stein U, Nasca S, Metges J-P, Rixe O, Michel P, Magherini E, Hua A, Deplanque G. Irinotecan plus oxaliplatin and leucovorin-modulated fluorouracil in advanced pancreatic cancer--a Groupe Tumeurs Digestives of the Federation Nationale des Centres de Lutte Contre le Cancer study. J. Clin. Oncol. 2005; 23: 1228-1236.

38. Pelzer U, Schwaner I, Stieler J, Adler M, Seraphin J, Dörken B, Riess H, Oettle H. Best supportive care (BSC) versus oxaliplatin, folinic acid and 5fluorouracil (OFF) plus BSC in patients for second-line advanced pancreatic cancer: a phase III-study from the German CONKO-study group. Eur. J. Cancer 1990 2011; 47: 1676-1681.

39. Taylor SE, Beck TL, Krivak TC, Zorn KK, Kelley JL, Edwards RP. Oxaliplatin salvage for recurrent ovarian cancer: a single institution's 
experience in patient populations with platinum resistant disease or a history of platinum hypersensitivity. Gynecol. Oncol. 2014; 134: 68-72.

40. Sakaeda T, Kadoyama K, Yabuuchi H, Niijima S, Seki K, Shiraishi Y, Okuno Y. Platinum agent-induced hypersensitivity reactions: data mining of the public version of the FDA adverse event reporting system, AERS. Int. J. Med. Sci. 2011; 8: 332-338.

41. Schwartz JR, Bandera C, Bradley A, Brard L, Legare R, Granai CO, Dizon DS. Does the platinum-free interval predict the incidence or severity of hypersensitivity reactions to carboplatin? The experience from Women and Infants' Hospital. Gynecol. Oncol. 2007; 105: 81-83.

42. Caiado J, Venemalm L, Pereira-Santos MC, Costa L, Barbosa MP, Castells M. Carboplatin-, Oxaliplatin-, and Cisplatin-specific IgE: Crossreactivity and Value in the Diagnosis of Carboplatin and Oxaliplatin Allergy. J. Allergy Clin. Immunol. Pract. 2013; 1: 494-500.

43. Maindrault-Goebel F, André T, Tournigand C, Louvet C, Perez-Staub N, Zeghib N, De Gramont A. Allergic-type reactions to oxaliplatin: retrospective analysis of 42 patients. Eur. J. Cancer 1990 2005; 41: 2262-2267.

44. Price KS, Castells MC. Taxol reactions. Allergy Asthma Proc. 2002; 23: 205-208.

45. Jogie-Brahim S, Min H-K, Fukuoka Y, Xia H-Z, Schwartz LB. Expression of alpha-tryptase and beta-tryptase by human basophils. J. Allergy Clin. Immunol. 2004; 113: 1086-1092.

46. Mertes PM, Malinovsky JM, Jouffroy L, Working Group of the SFAR and SFA, Aberer W, Terreehorst I, Brockow K, Demoly P, ENDA, EAACI 
Interest Group on Drug Allergy. Reducing the risk of anaphylaxis during anesthesia: 2011 updated guidelines for clinical practice. J. Investig. Allergol. Clin. Immunol. 2011; 21: 442-453.

47. Mertes P-M, Laxenaire M-C, GERAP. [Anaphylactic and anaphylactoid reactions occurring during anaesthesia in France. Seventh epidemiologic survey (January 2001-December 2002)]. Ann. Fr. Anesthèsie Rèanimation 2004; 23: 1133-1143.

48. Fisher MM, Baldo BA. Mast cell tryptase in anaesthetic anaphylactoid reactions. Br. J. Anaesth. 1998; 80: 26-29.

49. Ebo DG, Fisher MM, Hagendorens MM, Bridts $\mathrm{CH}$, Stevens WJ. Anaphylaxis during anaesthesia: diagnostic approach. Allergy 2007; 62: 471-487.

50. Laroche D, Vergnaud MC, Sillard B, Soufarapis H, Bricard H. Biochemical markers of anaphylactoid reactions to drugs. Comparison of plasma histamine and tryptase. Anesthesiology 1991; 75: 945-949.

51. Sala-Cunill A, Cardona V, Labrador-Horrillo M, Luengo O, Esteso O, Garriga T, Vicario M, Guilarte M. Usefulness and limitations of sequential serum tryptase for the diagnosis of anaphylaxis in 102 patients. Int. Arch. Allergy Immunol. 2013; 160: 192-199.

52. Schwartz LB, Yunginger JW, Miller J, Bokhari R, Dull D. Time course of appearance and disappearance of human mast cell tryptase in the circulation after anaphylaxis. J. Clin. Invest. 1989; 83: 1551-1555.

53. Galvão VR, Castells MC. Hypersensitivity to biological agents-updated diagnosis, management, and treatment. J. Allergy Clin. Immunol. Pract. 2015; 3: 175-185. 
54. Galvão VR, Giavina-Bianchi P, Castells M. Perioperative anaphylaxis. Curr. Allergy Asthma Rep. 2014; 14: 452.

55. Michalska-Krzanowska G. Tryptase in diagnosing adverse suspected anaphylactic reaction. Adv. Clin. Exp. Med. 2012; 21: 403-408.

56. Dewachter P, Mouton-Faivre C, Emala CW. Anaphylaxis and anesthesia: controversies and new insights. Anesthesiology 2009; 111: 1141-1150.

57. Schwartz LB, Sakai K, Bradford TR, Ren S, Zweiman B, Worobec AS, Metcalfe DD. The alpha form of human tryptase is the predominant type present in blood at baseline in normal subjects and is elevated in those with systemic mastocytosis. J. Clin. Invest. 1995; 96: 2702-2710.

58. Akin C, Soto D, Brittain E, Chhabra A, Schwartz LB, Caughey GH, Metcalfe DD. Tryptase haplotype in mastocytosis: relationship to disease variant and diagnostic utility of total tryptase levels. Clin. Immunol. 2007; 123: 268-271.

59. Korosec P, Turner PJ, Silar M, Kopac P, Kosnik M, Gibbs BF, Shamji MH, Custovic A, Rijavec M. Basophils, high-affinity lgE receptors, and CCL2 in human anaphylaxis. J. Allergy Clin. Immunol. 2017; 140: 750-758.

60. Kleine-Tebbe J, Erdmann S, Knol EF, MacGlashan DWJ, Poulsen LK, Gibbs BF. Diagnostic tests based on human basophils: potentials, pitfalls and perspectives. Int. Arch. Allergy Immunol. 2006; 141: 79-90.

61. Knol EF, Mul FP, Jansen H, Calafat J, Roos D. Monitoring human basophil activation via CD63 monoclonal antibody 435. J. Allergy Clin. Immunol. 1991; 88: 328-338. 
62. Monneret G, Gutowski MC, Bienvenu J. Detection of allergen-induced basophil activation by expression of CD63 antigen using a tricolour flow cytometric method. Clin. Exp. Immunol. 1999; 115: 393-396.

63. Bühring HJ, Seiffert M, Giesert C, Marxer A, Kanz L, Valent P, Sano K. The basophil activation marker defined by antibody $97 \mathrm{~A} 6$ is identical to the ectonucleotide pyrophosphatase/phosphodiesterase 3. Blood 2001; 97: 3303-3305.

64. Bühring HJ, Simmons PJ, Pudney $M$, Müller $R$, Jarrossay $D$, van Agthoven A, Willheim M, Brugger W, Valent P, Kanz L. The monoclonal antibody 97A6 defines a novel surface antigen expressed on human basophils and their multipotent and unipotent progenitors. Blood 1999; 94 : 2343-2356.

65. Sturm EM, Kranzelbinder B, Heinemann A, Groselj-Strele A, Aberer W, Sturm GJ. CD203c-based basophil activation test in allergy diagnosis: characteristics and differences to CD63 upregulation. Cytometry B Clin. Cytom. 2010; 78: 308-318.

66. Boumiza R, Monneret G, Forissier M-F, Savoye J, Gutowski M-C, Powell WS, Bienvenu J. Marked improvement of the basophil activation test by detecting CD203c instead of CD63. Clin. Exp. Allergy 2003; 33: 259-265.

67. Eberlein-König B, Varga R, Mempel M, Darsow U, Behrendt H, Ring J. Comparison of basophil activation tests using CD63 or CD203c expression in patients with insect venom allergy. Allergy 2006; 61: 10841085. 
68. de Weck AL, Sanz ML. For allergy diagnostic flow cytometry, detection of CD203c instead of CD63 is not at all an improvement in other hands. Clin. Exp. Allergy 2003; 33: 849-852; author reply 852-853.

69. Ebo DG, Lechkar B, Schuerwegh AJ, Bridts CH, De Clerck LS, Stevens WJ. Comments regarding "Marked improvement of the basophil activation test by detecting CD203c instead of CD63" by Boumiza et al. Clin. Exp. Allergy 2003; 33: 849; author reply 852-853.

70. Sudheer PS, Hall JE, Read GF, Rowbottom AW, Williams PE. Flow cytometric investigation of peri-anaesthetic anaphylaxis using CD63 and CD203c. Anaesthesia 2005; 60: 251-256.

71. Ford LS, Bloom KA, Nowak-Węgrzyn AH, Shreffler WG, Masilamani M, Sampson HA. Basophil reactivity, wheal size, and immunoglobulin levels distinguish degrees of cow's milk tolerance. J. Allergy Clin. Immunol. 2013; 131: 180-186.e1-3.

72. Wanich N, Nowak-Wegrzyn A, Sampson HA, Shreffler WG. Allergenspecific basophil suppression associated with clinical tolerance in patients with milk allergy. J. Allergy Clin. Immunol. 2009; 123: 789-794.e20.

73. de Weck AL, Sanz ML, Gamboa PM, Aberer W, Bienvenu J, Blanca M, Demoly P, Ebo DG, Mayorga L, Monneret G, Sainte-Laudy J. Diagnostic tests based on human basophils: more potentials and perspectives than pitfalls. Int. Arch. Allergy Immunol. 2008; 146: 177-189.

74. Shreffler WG. Evaluation of basophil activation in food allergy: present and future applications. Curr. Opin. Allergy Clin. Immunol. 2006; 6: 226233. 
75. Balzer L, Pennino D, Blank S, Seismann H, Darsow U, Schnedler M, McIntyre M, Ollert MW, Durham SR, Spillner E, Ring J, Cifuentes L. Basophil activation test using recombinant allergens: highly specific diagnostic method complementing routine tests in wasp venom allergy. PloS One 2014; 9: e108619.

76. Ocmant A, Peignois $\mathrm{Y}$, Mulier S, Hanssens L, Michils A, Schandené L. Flow cytometry for basophil activation markers: The measurement of CD203c up-regulation is as reliable as CD63 expression in the diagnosis of cat allergy. J. Immunol. Methods 2007; 320: 40-48.

77. Ebo DG, Hagendorens MM, Bridts CH, De Clerck LS, Stevens WJ. Hymenoptera venom allergy: taking the sting out of difficult cases. J. Investig. Allergol. Clin. Immunol. 2007; 17: 357-360.

78. Bidad K, Nawijn MC, van Oosterhout AJM, van der Heide S, Elberink JNGO. Basophil activation test in the diagnosis and monitoring of mastocytosis patients with wasp venom allergy on immunotherapy. Cytometry B Clin. Cytom. 2014; 86: 183-190.

79. Rubio A, Vivinus-Nébot M, Bourrier T, Saggio B, Albertini M, Bernard A. Benefit of the basophil activation test in deciding when to reintroduce cow's milk in allergic children. Allergy 2011; 66: 92-100.

80. Song W-J, Chang Y-S. Recent applications of basophil activation tests in the diagnosis of drug hypersensitivity. Asia Pac. Allergy 2013; 3: 266280.

81. Steiner M, Harrer A, Himly M. Basophil Reactivity as Biomarker in Immediate Drug Hypersensitivity Reactions-Potential and Limitations. Front. Pharmacol. 2016; 7: 171. 
82. Aranda A, Mayorga C, Ariza A, Doña I, Rosado A, Blanca-Lopez N, Andreu I, Torres MJ. In vitro evaluation of $\lg E$-mediated hypersensitivity reactions to quinolones. Allergy 2011; 66: 247-254.

83. González-de-Olano D, Morgado JM, Juárez-Guerrero R, Sánchez-Muñoz L, Letellez-Fernández J, Malón-Giménez D, Castells MC. Positive basophil activation test following anaphylaxis to pertuzumab and successful treatment with rapid desensitization. J. Allergy Clin. Immunol. Pract. 2016; 4: 338-340.

84. Viardot-Helmer A, Ott H, Sauer I, Merk HF. [Basophil activation test as in vitro assay for cisplatin allergy]. Hautarzt 2008; 59: 883-884.

85. Ebo DG, Bridts $\mathrm{CH}$, Hagendorens $\mathrm{MM}$, Mertens $\mathrm{CH}$, De Clerck LS, Stevens WJ. Flow-assisted diagnostic management of anaphylaxis from rocuronium bromide. Allergy 2006; 61: 935-939.

86. Leysen J, Bridts CH, De Clerck LS, Vercauteren M, Lambert J, Weyler JJ, Stevens WJ, Ebo DG. Allergy to rocuronium: from clinical suspicion to correct diagnosis. Allergy 2011; 66: 1014-1019.

87. Sanz ML, Gamboa PM, Antépara I, Uasuf C, Vila L, Garcia-Avilés C, Chazot M, De Weck AL. Flow cytometric basophil activation test by detection of CD63 expression in patients with immediate-type reactions to betalactam antibiotics. Clin. Exp. Allergy 2002; 32: 277-286.

88. Iwamoto T, Yuta A, Tabata T, Sugimoto H, Gabazza EC, Hirai H, Kojima S, Okuda M. Evaluation of basophil CD203c as a predictor of carboplatinrelated hypersensitivity reaction in patients with gynecologic cancer. Biol. Pharm. Bull. 2012; 35: 1487-1495. 
89. Iwamoto T, Hirai H, Yamaguchi N, Kobayashi N, Sugimoto H, Tabata T, Okuda M. Carboplatin-induced severe hypersensitivity reaction: role of IgE-dependent basophil activation and FceRI. Cancer Sci. 2014; 105: 1472-1479.

90. Cernadas JR, Brockow K, Romano A, Aberer W, Torres MJ, Bircher A, Campi P, Sanz ML, Castells M, Demoly P, Pichler WJ, European Network of Drug Allergy and the EAACI interest group on drug hypersensitivity. General considerations on rapid desensitization for drug hypersensitivity a consensus statement. Allergy 2010; 65: 1357-1366.

91. Castells M. Desensitization for drug allergy. Curr. Opin. Allergy Clin. Immunol. 2006; 6: 476-481.

92. Shalit M, Levi-Schaffer F. Challenge of mast cells with increasing amounts of antigen induces desensitization. Clin. Exp. Allergy 1995; 25: 896-902.

93. Sancho-Serra M del C, Simarro M, Castells M. Rapid IgE desensitization is antigen specific and impairs early and late mast cell responses targeting FceRI internalization. Eur. J. Immunol. 2011; 41: 1004-1013.

94. Morales AR, Shah N, Castells M. Antigen-lgE desensitization in signal transducer and activator of transcription 6-deficient mast cells by suboptimal doses of antigen. Ann. Allergy Asthma Immunol. 2005; 94: $575-580$.

95. Kepley CL. Antigen-induced reduction in mast cell and basophil functional responses due to reduced Syk protein levels. Int. Arch. Allergy Immunol. 2005; 138: 29-39.

96. du Bois A, Lück H-J, Meier W, Adams H-P, Möbus V, Costa S, Bauknecht T, Richter B, Warm M, Schröder W, Olbricht S, Nitz U, Jackisch C, Emons 
G, Wagner U, Kuhn W, Pfisterer J, Arbeitsgemeinschaft Gynäkologische Onkologie Ovarian Cancer Study Group. A randomized clinical trial of cisplatin/paclitaxel versus carboplatin/paclitaxel as first-line treatment of ovarian cancer. J. Natl. Cancer Inst. 2003; 95: 1320-1329.

97. Guastalla JP, Pujade-Lauraine E, Weber B, Cuŕe H, Orfeuvre H, Mousseau $M$, Vincent $P$, Diéras $V$, Tubiana-Mathieu $N$, Jacquin JP, Mignot L, Leduc B, Viens P, Pariso D. Efficacy and safety of the paclitaxel and carboplatin combination in patients with previously treated advanced ovarian carcinoma. A multicenter GINECO (Group d'Investigateurs Nationaux pour l'Etude des Cancers Ovariens) phase II study. Ann. Oncol. 1998; 9: 37-43.

98. Falcetta FS, Medeiros LR, Edelweiss MI, Pohlmann PR, Stein AT, Rosa DD. Adjuvant platinum-based chemotherapy for early stage cervical cancer. Cochrane Database Syst. Rev. 2016; 11: CD005342.

99. Sloane D, Govindarajulu U, Harrow-Mortelliti J, Barry W, Hsu FI, Hong D, Laidlaw T, Palis R, Legere H, Bunyavanich S, Breslow R, Wesemann D, Barrett N, Brennan P, Chong HJ, Liu A, Fernandez J, Fanning L, Kyin T, Cahill K, Bankova L, Lynch A, Berlin S, Campos S, Fuchs C, Mayer R, Matulonis U, Castells M. Safety, Costs, and Efficacy of Rapid Drug Desensitizations to Chemotherapy and Monoclonal Antibodies. J. Allergy Clin. Immunol. Pract. 2016; 4: 497-504.

100. del Carmen Sancho M, Breslow R, Sloane D, Castells M. Desensitization for hypersensitivity reactions to medications. Chem. Immunol. Allergy 2012; 97: 217-233. 
101. Brennan PJ, Rodriguez Bouza T, Hsu FI, Sloane DE, Castells MC. Hypersensitivity reactions to mAbs: 105 desensitizations in 23 patients, from evaluation to treatment. J. Allergy Clin. Immunol. 2009; 124: 12591266.

102. Mezzano V, Giavina-Bianchi P, Picard M, Caiado J, Castells M. Drug desensitization in the management of hypersensitivity reactions to monoclonal antibodies and chemotherapy. BioDrugs 2014; 28: 133-144.

103. Peshkin BN, Isaacs C. Genetic risk assessment for individuals at risk for hereditary breast and ovarian cancer syndromes. [Internet] UpToDate; 2015. Disponível em: https://www.uptodate.com/contents/geneticcounseling-and-testing-for-hereditary-breast-and-ovarian-cancer

104. Mersch J, Jackson MA, Park M, Nebgen D, Peterson SK, Singletary C, Arun BK, Litton JK. Cancers associated with BRCA1 and BRCA2 mutations other than breast and ovarian. Cancer 2015; 121: 269-275.

105. Tai YC, Domchek S, Parmigiani G, Chen S. Breast cancer risk among male BRCA1 and BRCA2 mutation carriers. J. Natl. Cancer Inst. 2007; 99: $1811-1814$.

106. Moon DH, Lee J-M, Noonan AM, Annunziata CM, Minasian L, Houston N, Hays JL, Kohn EC. Deleterious BRCA1/2 mutation is an independent risk factor for carboplatin hypersensitivity reactions. Br. J. Cancer 2013; 109 : 1072-1078.

107. Anders, CK; Carey, LA. Epidemiology, risk factors and the clinical approach to ER/PR negative, HER2-negative (Triple-negative) breast cancer. [Internet] UpToDate; 2015. Disponível em: https://www.uptodate.com/contents/epidemiology-risk-factors-and-the- 
clinical-approach-to-er-pr-negative-her2-negative-triple-negative-breastcancer

108. Alsop K, Fereday S, Meldrum C, deFazio A, Emmanuel C, George J, Dobrovic A, Birrer MJ, Webb PM, Stewart C, Friedlander M, Fox S, Bowtell D, Mitchell G. BRCA mutation frequency and patterns of treatment response in BRCA mutation-positive women with ovarian cancer: a report from the Australian Ovarian Cancer Study Group. J. Clin. Oncol. 2012; 30: 2654-2663.

109. du Bois A, Quinn M, Thigpen T, Vermorken J, Avall-Lundqvist E, Bookman M, Bowtell D, Brady M, Casado A, Cervantes A, Eisenhauer E, Friedlaender M, Fujiwara K, Grenman S, Guastalla JP, Harper P, Hogberg T, Kaye S, Kitchener H, Kristensen G, Mannel R, Meier W, Miller B, Neijt JP, Oza A, Ozols R, Parmar M, Pecorelli S, Pfisterer J, Poveda A, et al. 2004 consensus statements on the management of ovarian cancer: final document of the 3rd International Gynecologic Cancer Intergroup Ovarian Cancer Consensus Conference (GCIG OCCC 2004). Ann. Oncol. 2005; 16 Suppl 8: viii7-viii12.

110. Brown SG. Clinical features and severity grading of anaphylaxis. J. Allergy Clin. Immunol. 2004; 114: 371-376.

111. Macy E, Contreras R. Health care use and serious infection prevalence associated with penicillin "allergy" in hospitalized patients: A cohort study. J. Allergy Clin. Immunol. 2014; 133: 790-796.

112. Parel M, Ranchon F, Nosbaum A, You B, Vantard N, Schwiertz V, Gourc C, Gauthier N, Guedat M-G, He S, Kiouris E, Alloux C, Vial T, Trillet- 
Lenoir V, Freyer G, Berard F, Rioufol C. Hypersensitivity to oxaliplatin: clinical features and risk factors. BMC Pharmacol. Toxicol. 2014; $15: 1$.

113. Kim BH, Bradley T, Tai J, Budman DR. Hypersensitivity to oxaliplatin: an investigation of incidence and risk factors, and literature review. Oncology 2009; 76: 231-238.

114. Hauswirth AW, Sonneck K, Florian S, Krauth MT, Bohm A, Sperr WR, Valenta R, Schernthaner GH, Printz D, Fritsch G, Buhring HJ, Valent P. Interleukin-3 promotes the expression of E-NPP3/CD203C on human blood basophils in healthy subjects and in patients with birch pollen allergy. Int. J. Immunopathol. Pharmacol. 2007; 20: 267-278.

115. Schwartz LB. Diagnostic value of tryptase in anaphylaxis and mastocytosis. Immunol. Allergy Clin. North Am. 2006; 26: 451-463.

116. Giavina-Bianchi P, Galvão VR, Picard M, Caiado J, Castells MC. Basophil Activation Test is a Relevant Biomarker of the Outcome of Rapid Desensitization in Platinum Compounds-Allergy. J. Allergy Clin. Immunol. Pract. 2017; 5: 728-736.

117. Tung N, Lin NU, Kidd J, Allen BA, Singh N, Wenstrup RJ, Hartman A-R, Winer EP, Garber JE. Frequency of Germline Mutations in 25 Cancer Susceptibility Genes in a Sequential Series of Patients With Breast Cancer. J. Clin. Oncol. 2016; 34: 1460-1468.

118. Jiang Q, Greenberg RA. Deciphering the BRCA1 Tumor Suppressor Network. J. Biol. Chem. 2015; 290:17724-32.

119. Galvão VR, Phillips E, Giavina-Bianchi P, Castells MC. Carboplatinallergic patients undergoing desensitization: prevalence and impact of the BRCA 1/2 mutation. J. Allergy Clin. Immunol. Pract. 2017; 5: 816-818. 